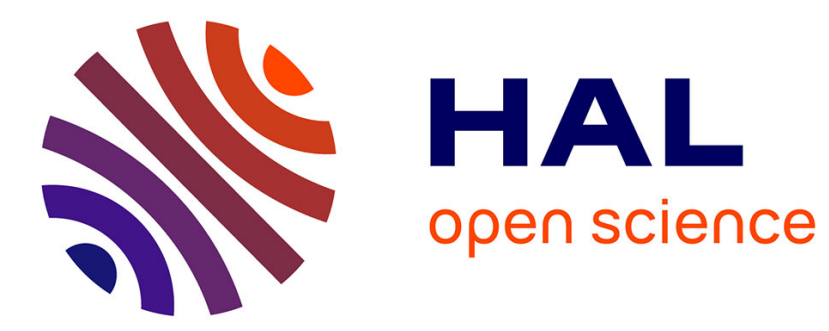

\title{
Potential of the Cross Biaxial Test for Anisotropy Characterization Based on Heterogeneous Strain Field
}

Shunying Zhang, Lionel Leotoing, Dominique Guines, Sandrine Thuillier

\section{To cite this version:}

Shunying Zhang, Lionel Leotoing, Dominique Guines, Sandrine Thuillier. Potential of the Cross Biaxial Test for Anisotropy Characterization Based on Heterogeneous Strain Field. Experimental Mechanics, 2015, 55 (5), pp.817-835. 10.1007/s11340-014-9983-y . hal-01151222

\author{
HAL Id: hal-01151222 \\ https://hal.science/hal-01151222
}

Submitted on 12 May 2015

HAL is a multi-disciplinary open access archive for the deposit and dissemination of scientific research documents, whether they are published or not. The documents may come from teaching and research institutions in France or abroad, or from public or private research centers.
L'archive ouverte pluridisciplinaire HAL, est destinée au dépôt et à la diffusion de documents scientifiques de niveau recherche, publiés ou non, émanant des établissements d'enseignement et de recherche français ou étrangers, des laboratoires publics ou privés. 


\title{
Potential of the cross biaxial test for anisotropy characterization based on heterogeneous strain field
}

\author{
ZHANG Shunying ${ }^{1}$, LEOTOING Lionel ${ }^{1}$, GUINES Dominique ${ }^{1}$, THUILLIER \\ Sandrine ${ }^{2}$
}

${ }^{1}$ LGCGM, INSA, UEB, 20 avenue des Buttes de Coësmes, 35708 Rennes Cedex France

${ }^{2}$ Univ. Bretagne-Sud, EA 4250, LIMATB, F-56100 Lorient, France

\begin{abstract}
The mechanical behavior in cross biaxial tension was investigated for two metallic sheets, an aluminium alloy and a dual phase steel. The heterogeneous strain field in the central gauge area of a cruciform specimen was analyzed by digital image correlation. Minor and major strains were output along several paths, for a given load level just before necking, showing a wide range of strain states, from uniaxial tension to biaxial state. The applied loads along the two loading directions were also recorded, the gap between the two signals being all the most important that the material anisotropy was significant. Moreover, the strain path ratio, defined as the ratio of the minor strain over the major strain, exhibited a sensible non-monotonic evolution along the transverse direction, compared to the rolling direction. Finally, a material parameter identification process with only biaxial tensile test for Bron and Besson anisotropic yield model was proposed, based on the minimization of experimental and numerical principal strains along a specified path in the gauge area of the cruciform specimen.
\end{abstract}

\section{Introduction}

Sheet metals usually exhibit an orthotropic behavior related to the rolling process. Such an anisotropy influences the final geometry of deep-drawn parts, stress level prediction in finite element simulations as well as the strain at rupture. Within a phenomenological description of the mechanical behavior of sheet metals, this phenomenon is classically represented with anisotropic yield functions, considering that the initial anisotropy, as determined just at the 
elasto-plastic transition, does not evolve with plastic strain. A very large number of anisotropic yield criteria have already been proposed, e.g. [1-4], and the models tend to become more and more complex involving more and more material parameters, which leads to a great flexibility to describe the anisotropic behavior at different stress and strain states. In this study, a yield function based on two transformation tensors and involving 16 material parameters was chosen [5]. However, such yield function with numerous parameters requires an extensive experimental database and therefore a complex identification strategy.

A first approach for material parameter identification is to consider several quasi-homogeneous mechanical tests in the experimental database. The frequently used tests are: uniaxial tension, simple shear, planar tension and biaxial tension obtained by hydraulic bulging, which are in the following called conventional tests [6]. They are either considered homogeneous, leading to an analytical post-treatment of raw data, e.g. uniaxial tension and simple shear, or at least the post-treatment is limited to a reduced area like in hydraulic bulging. The identification method is usually based on adjusting, either in a direct way or by an inverse procedure, the yield model parameters for several signals obtained from conventional tests; very often, initial yield stresses and anisotropic coefficients are considered in the experimental database [2, 7-11]. However, it was pointed out that due to the dispersion on initial yield stresses as well as the evolution of anisotropy with strain, considering only initial values does not give an accurate description of the mechanical behavior [12]. Moreover, the anisotropic model should be able to address all the experimental results: initial data and also subsequent data at least over a given strain range. Some works investigated the identification of material parameters considering not only the initial values but also values recorded at higher strains. Bron and Besson [5] and Zang et al. [13] identified Bron and Besson yield model parameters, for plane stress states, by considering plastic anisotropy coefficients as well as the full strain-stress curves for several conventional tests. Some studies proposed non-constant material parameters, that depended on the plastic strain [12-15]. However, with this method, more 
material parameters were introduced. Moreover, each conventional test corresponds usually to a unique strain state, i.e. monotonic loading, and therefore a multi-parameter identification process requires several conventional tests.

An interesting alternative can consist in performing identification process with data from a heterogeneous test, so that different strain states can be obtained with only one specimen. As the techniques to measure displacement and strain fields have developed, parameter identification of mechanical models with the whole heterogeneous strain field has been performed [16]. Among the different possibilities to perform parameter identification from full-field measurements, one possibility is to use finite element model updating method or FEMU [17]. It consists of decreasing the gap between finite element simulation output and experiments, by optimizing the material parameters. For example, Güner et al. [18] propose to use heterogeneous tensile tests to identify the anisotropy of an AA6016-T4 sheet described with the Yld2000-2D model. The method includes the optical measurement of strains on three flat specimens with varying cross-section and an inverse parameter identification scheme, which minimizes the differences between the numerical simulation strain fields and the experimental ones. The specimen allows different strain states between uniaxial tension and plane strain tension. The equi-biaxial stress state is obtained from a layer compression test, which is also included in the experimental database. Several parameters of a constitutive model can be identified at the same time with only one test when the experimental field information is rich enough [19]. For example, Pottier et al. [20] proposed an inverse identification procedure with out-of-plane displacement and deformation field measurement. The sample was designed to exhibit tension, shear and expansion strain states. Parameters (4) of Hill 1948 yield model written for a plane stress state, together with parameters of a hardening law (2), were identified by comparing the experimental and numerical displacements along three directions as well as the tool reaction force. However, extracting relevant information from inhomogeneous strain fields is a vast task that necessitates dedicated strategies. Lubineau [21] highlighted that 
material parameters may affect differently the mechanical response depending on the material point and therefore proposed an automated treatment, via filtering, of the information. However, it led to high computational times even though only 2 material parameters were used. Indeed, the development of such strategies is in itself a research work, and their applications were restricted to a small number of material parameters and to virtual materials [22]. The focus of this work is to consider a large number of material parameters identified from experimental data.

Biaxial tensile test with a cruciform specimen seems to be also promising to reach different strain states. Indeed, this test seems particularly interesting since different strain paths can be obtained simultaneously with a unique specimen shape by imposing different loads or velocity on two arms [23]. Prates [24] proposed an inverse analysis methodology to determine the parameters of Hill 1948 yield criterion with a cruciform specimen. Principal strains along rolling and transverse directions (RD and TD respectively) from the specimen center were measured and output. During the identification process, the parameters were adjusted by minimizing the difference between experimental and numerical equivalent strain and strain path ratio, defined as the ratio of the minor strain over the major strain. Teaca [25] also proposed a parameter identification procedure with two designed cruciform specimens, which offered high sensitivity of strain field along the arms. To identify the parameters of an anisotropic yield function [26], strain field along rolling and diagonal directions were determined experimentally and numerically. During the identification process, two parameters of the yield model were adjusted by minimizing the difference between experimental and numerical strain field along rolling direction. The remaining parameters were determined from uniaxial tensile test data. Several mechanical tests were still required.

By itself, biaxial tension of cruciform specimen has presented a continuous interest among the mechanical community. Several mechanical design were tested to reach the biaxial strain or 
stress state, e.g. using two tensile loading systems [27], or a dedicated set-up installed on a tensile machine with jointed arms [28], or a transformation of the vertical displacement of the machine into horizontal ones [29]. Specific devices were also designed using servo-hydraulic actuators $[30,31]$. Signals recorded during the test are the loads in the two orthogonal directions and the strains, either with an extensometer [32] or digital image correlation [33]. The mechanical design of the cruciform specimen is the main difficulty and clearly the main limitation for an extensive use of cruciform biaxial tension. A lot of different shapes have been proposed, leading to a difficult comparison of the results; they can be classified into three main categories [34], i.e. cut type, reduced section type and slot type specimen. The main aim is to reduce the strain in the arms and to increase the strain in the central area, and in some case to promote rupture in the central area, e.g. [35] for a survey of the different proposed geometries. It should also be emphasized that the choice of the geometry depends on the application, like measure of elasto-plastic yield stresses under different strain states [9, 10, 36-39] within a limited strain range or characterization of forming limit curves up to very high strains [40].

According to the literature survey presented above, cross biaxial tension combined with strain field measure is a new technique applied to the identification of material parameters for metallic sheets materials, though already used for other types of materials. Indeed, a similar test and sample geometry were previously used for composites [41, 42] and elastomers [43]. It can be emphasized that in these studies, a maximum of 4 parameters were identified from the information of the biaxial test. Up to now and to the authors' knowledge, there was no published work that dealt with the parameter identification of a complex yield model involving a large number of parameters (i.e. above 10) with a single heterogeneous test.

In the present article, a cross biaxial tensile test was used to identify the parameters of Bron and Besson anisotropic yield model for AA5086 and DP980 sheets. Experimental results on load and strain fields showed that these two materials exhibit an anisotropy that is more 
significant for the aluminium alloy than for the steel. The strain fields in the central area of the cruciform specimen for both materials showed a large heterogeneity, both in magnitude and strain path ratio. Principal strains were output in several directions, i.e. diagonal, longitudinal and transverse, and it was shown a specific evolution of the strain path ratio along the longitudinal direction, all the more important that the material anisotropy is significant. Finally, Bron and Besson yield model parameter were identified based on an inverse optimization method that involves a numerical simulation of the biaxial test and a minimization of the gap between experimental and numerical values of the principal strains in the central area. Out of comparison's sake, and in order to highlight the sensitivity of the numerical strain field to the anisotropy model, numerical simulations using Hill 1948 yield model were also performed. Hence, the reliability of the proposed identification method with only a cross-biaxial tensile test was established.

\section{Experiments}

\subsection{Material}

Two different materials were used in this study, an aluminium alloy AA5086 provided in sheets of thickness $2 \mathrm{~mm}$ and dual phase steel DP980 sheets of thickness $1.75 \mathrm{~mm}$. Both materials were characterized in previous works in uniaxial tension $[35,44]$, and their mechanical properties are given in Table 1. It can be seen that the aluminium alloy exhibits a significant normal anisotropy, as evidenced by an average plastic anisotropy coefficient, $\overline{\mathrm{r}}=\left(\mathrm{r}_{0}+2 \mathrm{r}_{45}+\mathrm{r}_{90}\right) / 4$, well below unity whereas DP980 exhibits a value closer to the isotropic

value. Both materials show a weak in-plane anisotropy, as evidenced by $|\Delta r|=\left(r_{0}-2 r_{45}+r_{90}\right) / 2$, where $r_{0}, r_{45}$ and $r_{90}$ are the three plastic anisotropic coefficients defined by the ratio of width plastic strain rate to normal plastic strain rate. Finally, the ultimate tensile strength $R_{m}$ of DP980 is 3.6 times higher than the one for AA5086. 
Table 1 Mechanical properties of AA5086 and DP980

\begin{tabular}{|c|c|c|c|c|c|c|c|c|c|}
\hline & \multirow{2}{*}{$\mathrm{r}_{0}$} & \multirow{2}{*}{$\mathrm{r}_{45}$} & \multirow{2}{*}{$\mathrm{r}_{90}$} & \multirow{2}{*}{$\overline{\mathrm{r}}$} & \multirow{2}{*}{$|\Delta \mathrm{r}|$} & \multicolumn{3}{|c|}{$\mathrm{R}_{\mathrm{p}} 0.2 \%(\mathrm{MPa})$} & \multirow{2}{*}{$\mathrm{R}_{\mathrm{m}}(\mathrm{MPa})$} \\
\hline & & & & & & $0^{\circ}$ & $45^{\circ}$ & $90^{\circ}$ & \\
\hline AA5086 & 0.39 & 0.47 & 0.4 & 0.437 & 0.015 & 146 & 131 & 130 & 270 \\
\hline DP980 & 0.63 & 0.95 & 0.84 & 0.815 & 0.05 & 701 & 690 & 694 & 973 \\
\hline
\end{tabular}

\subsection{Biaxial tensile machine}

The biaxial device, available in the Laboratory of Civil and Mechanical Engineering (LGCGM) of National Institute of Applied Sciences (INSA) at Rennes, is displayed in Fig. 1. The apparatus is equipped with four hydraulic cylinders and accumulators, which allow static and dynamic tests for cruciform specimen, though in this study only quasi-static tests were performed. The maximum load capacity for each arm is $50 \mathrm{kN}$ and the cylinder speed can be cumulated up to 2 $\mathrm{m} / \mathrm{s}$. To impose different strain paths to the biaxial tensile specimen, different velocities along the two arms can be applied.

The specimen is settled in the center of the machine. It is connected to the load cell via a bi-articulated link (Fig. 2), leading to a pivot. Therefore, there is no transverse load applied to the sample, only loads along the direction of the arms.

The displacement sensors are located at the far extremities of the machine and therefore the real displacements at the sample arms are not known accurately. A high-speed digital camera and a lighting system are installed above the specimen to take synchronized pictures of the specimen and to record the material point displacements throughout the biaxial tensile process. In order to have a high accuracy, only the central square area of the cruciform specimen was considered. 


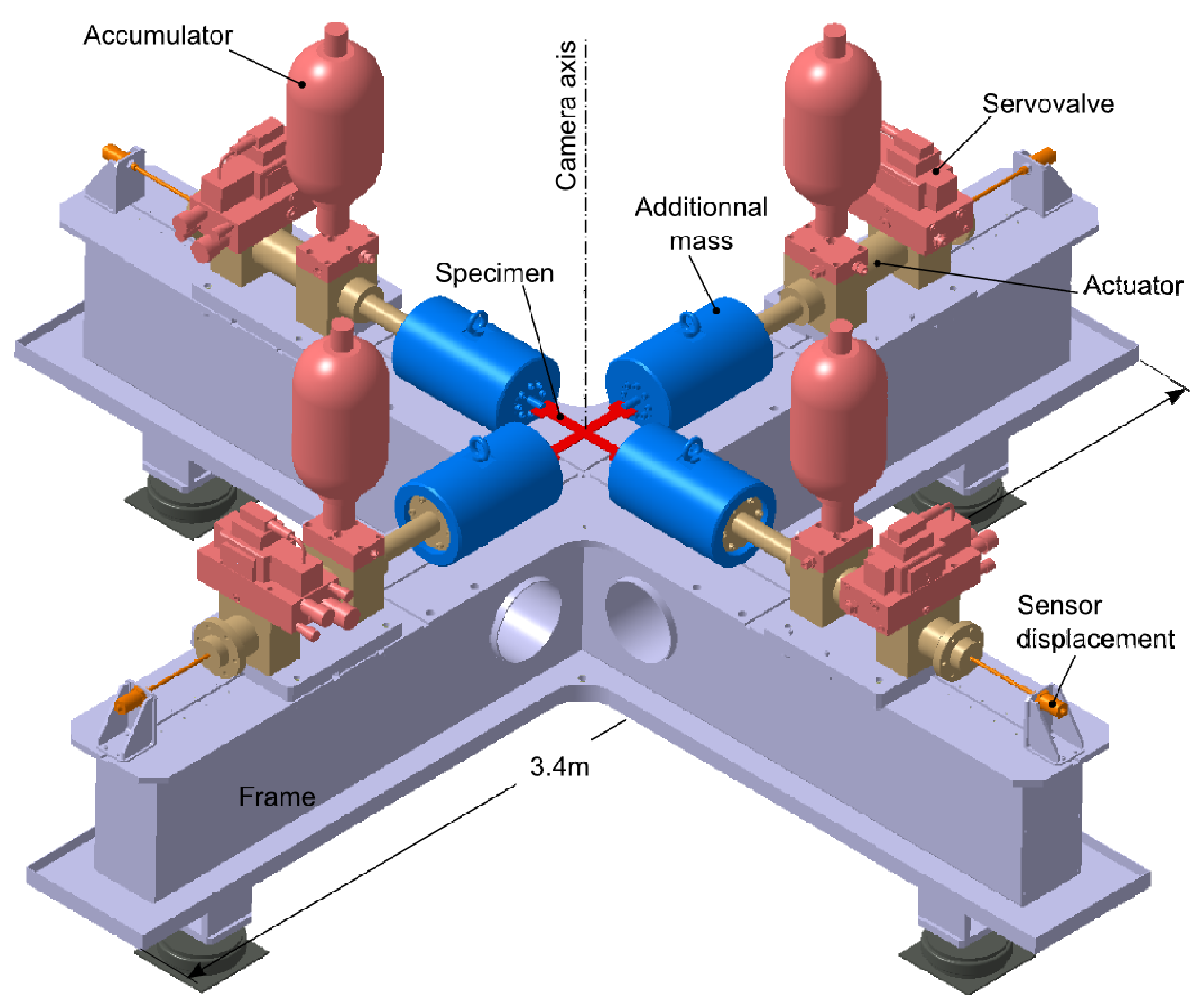

Fig. 1 Schematic representation of the biaxial tensile machine

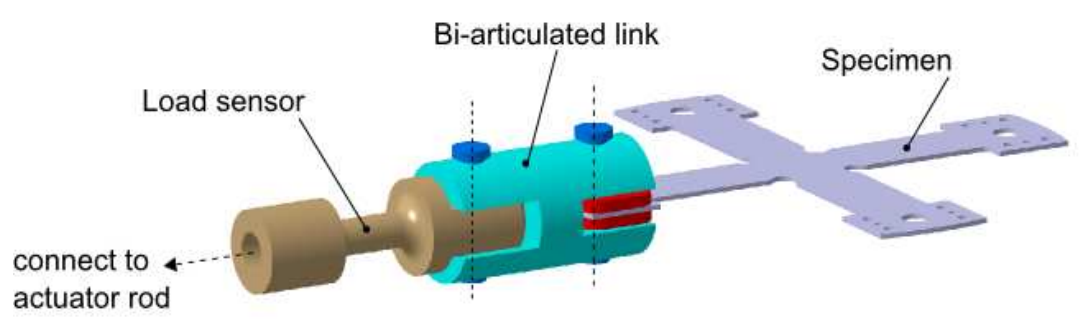

Fig. 2 Grip system to clamp the specimen

\subsection{Cruciform specimen}

Concerning the cruciform specimen shape, there is no normalized geometry and many different shapes have been proposed in the literature [40]. The main drawback of the cruciform specimen shape is the localization of the deformation between two adjacent arms leading to small levels of strain in 
the central area at rupture. The existing shapes can be classified into two main types: (i) the cut type with radius or notches between two adjacent arms $[10,36,37]$ and possibly with slots in the arms to reduce the strain localization at the corner of the two arms without reduction of the thickness. This type of cruciform specimen shape is the easiest one to manufacture and is usually chosen to characterize elastic properties or initial yield contours where low strain levels are required; (ii) the second type is the reduced section type where the thickness sheet is reduced in the central part of the specimen in order to ensure a localization of the deformation in this zone. Slots in the arms or notches can be also added to this type. With these specimen geometries, larger strain levels can be reached in the central zone before rupture occurs and hardening behavior or forming limits curves [40] can be characterized.

In this work, since large plastic strains are not necessarily required to capture initial yield contours, a simple specimen shape, a cut type one, with a radius of $5 \mathrm{~mm}$ between two arms has been chosen (Fig. 3). This specimen has no thickness reduction in its central area, so it can be used whatever the sheet thickness.

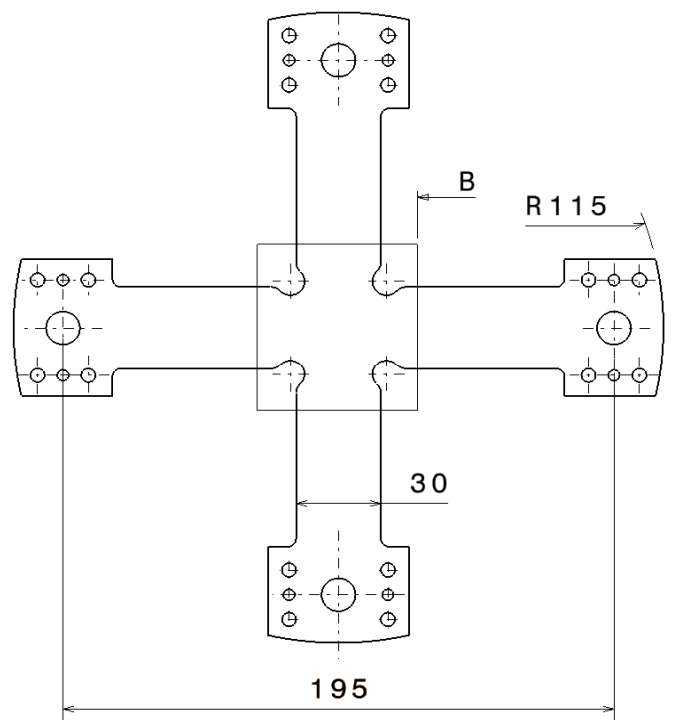

Détail B

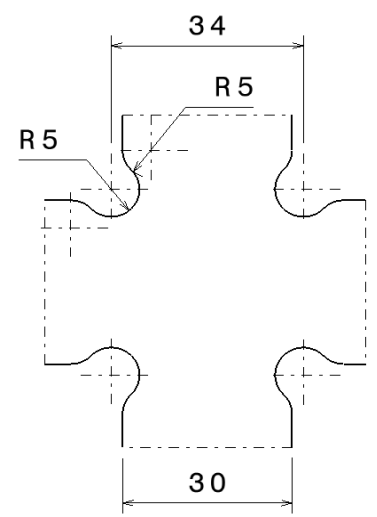

Fig. 3 Geometry of the cruciform specimen. Dimensions are given in $\mathbf{m m}$ 


\section{$2.4 \quad$ Experimental parameters}

Experiments on the servo-hydraulic device have been performed with a constant velocity ratio $\mathrm{v}_{\mathrm{x}} / \mathrm{v}_{\mathrm{y}}=1$ imposed on the four arms of the cruciform specimen, with $\mathrm{v}_{\mathrm{x}}=\mathrm{v}_{\mathrm{y}}=1 \mathrm{~mm} / \mathrm{s}$ the velocities imposed on the two arms, cf. Fig. 4 for the frame definition. $x$ and $y$ are along the rolling and transverse directions respectively.

Fig. 4 shows the image of the cruciform specimens before (initial state) and after the biaxial tensile tests for both materials: AA5086 and DP980. Two tests were performed for each material, in order to assess the reproducibility, specimen 1 and 2 are aluminium samples whereas specimen 3 and 4 refer to DP980 samples. Rupture of the samples occurred at time $t=6.048$ s for AA5086 (specimen 1) and $\mathrm{t}=3.240 \mathrm{~s}$ for DP980 (specimen 3). The rupture took place along the rolling direction for both materials, at the smallest section along one of the arm. For DP980, a second rupture was also obtained along $\mathrm{y}$ direction, since after the rupture along $\mathrm{x}$, the displacements were still imposed up to a fixed value.

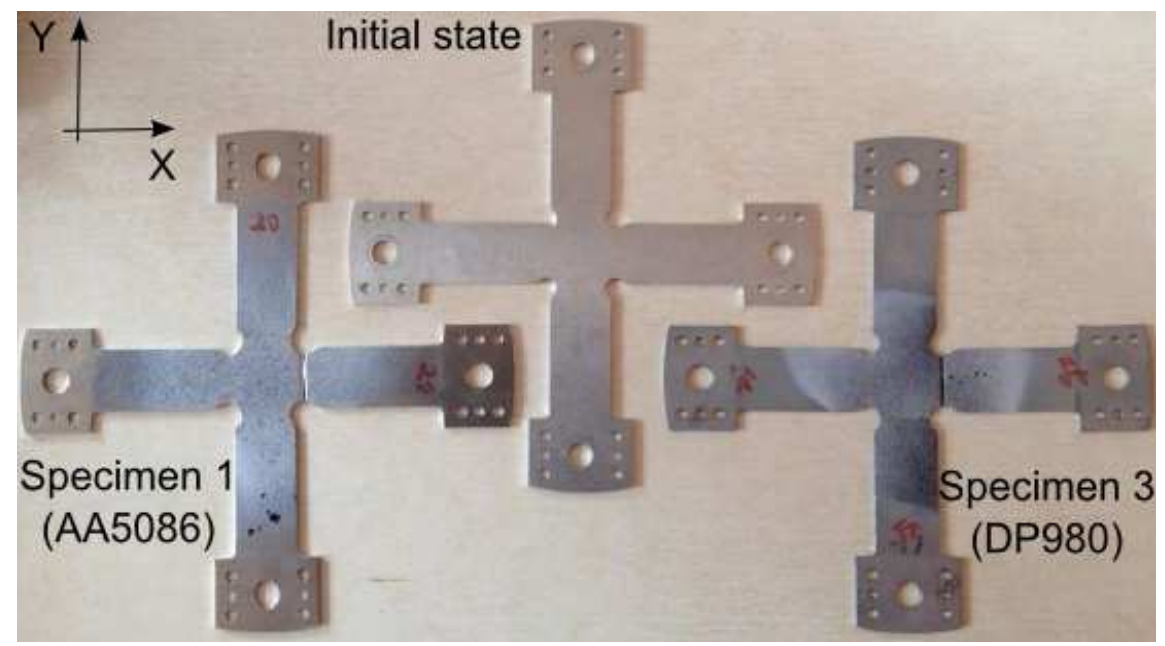

Fig. 4 Cruciform specimens before and after biaxial tensile test. Dimensions of the samples are given in Fig. 3

Fig. 5 and Fig. 6 show the evolution of the loads with time during the tests: $F_{X}$ and $F_{Y}$, for AA5086 and DP980 respectively. It can be seen that due to the material anisotropy, the force along rolling direction is about $5 \%$ higher than the one along transverse direction for AA5086, while for 
DP980, the force along the transverse direction is higher, by about $4.5 \%$, than the force along the rolling direction, before the necking. These results are consistent with the stress-strain data obtained in uniaxial tension in rolling and transverse directions for these materials [33, 44].

Moreover, due to the material and the thickness, a maximum load of $12 \mathrm{kN}$ was reached for AA5086 compared to $45 \mathrm{kN}$ for DP980. Also there exists a slight time shift between the loadings of the arms along two directions, in particular for AA5086 (Fig. 5). For DP980, the force along rolling direction exhibits a final decrease, before the rupture takes place, corresponding to necking (Fig. 6). While for the transverse direction, the still increasing force indicates that the necking did not occur along this arm.

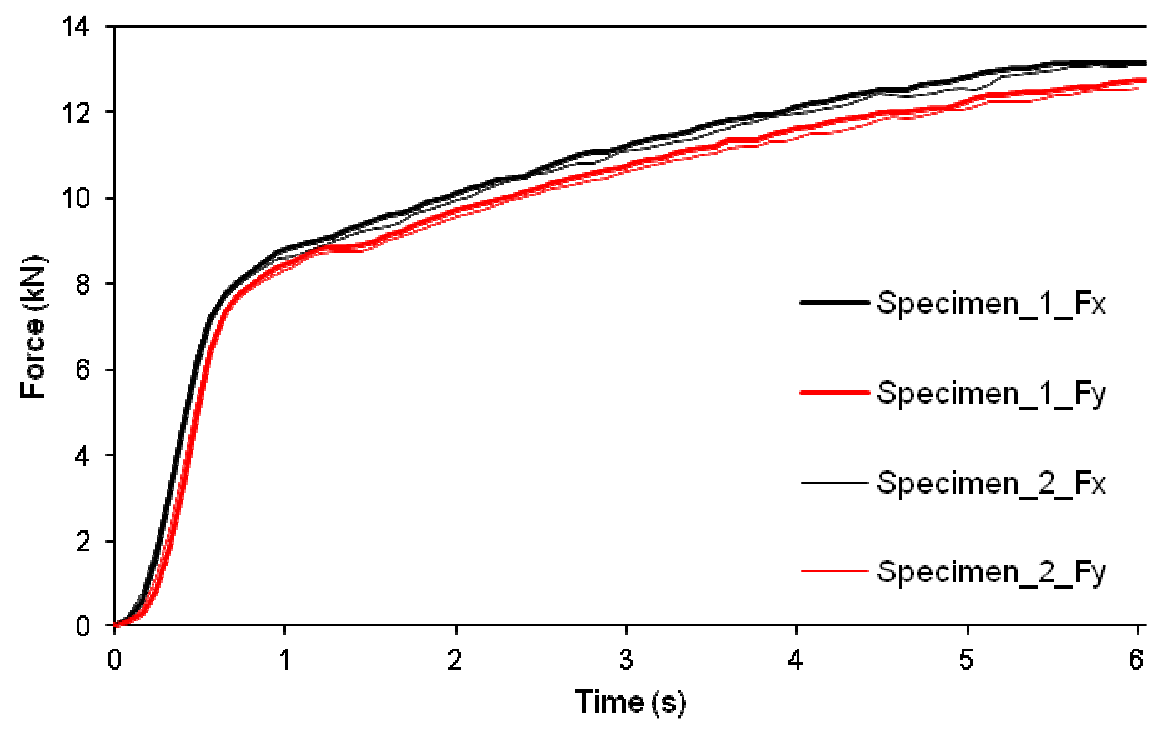

Fig. 5 Evolution of load with time along two arms for AA5086 specimens 


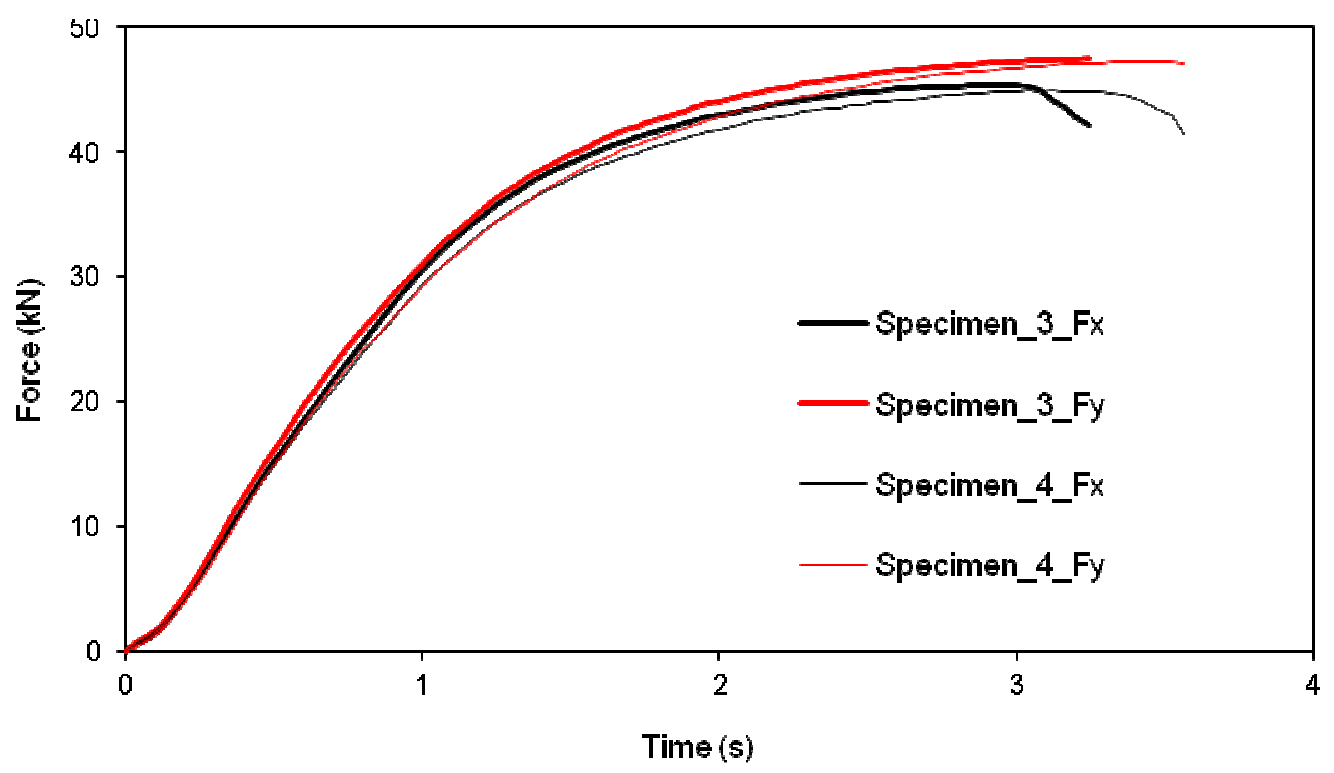

Fig. 6 Evolution of load with time along two arms for DP980 specimens

\section{Strain field measurement}

\subsection{Central area}

Images of the central area of the cruciform specimen were recorded with a high resolution camera. A frequency of 250 images/s is chosen. Considering the adopted image size and the dimensions of the filmed zone, a resolution of $0.419 \mathrm{~mm} /$ pixel is obtained. The DIC software CORRELA 2D was used to compute the in-plane strain tensor. Fig. 7 shows the different parameters of the calculation strain model used in current work. L and $\mathrm{H}$ define the subset size, D and $\mathrm{E}$ denote the distance between two sequential subsets in the $\mathrm{X}$ and $\mathrm{Y}$ direction. By setting the interval value $\mathrm{N}$, in-plane strains are calculated at the center of selected subsets, in grey color in Fig.7, from displacements of subsets. In this study, $\mathrm{L}$ and $\mathrm{H}$ were both set to 32 pixels and in order to obtain more strain points with DIC method, D and E were both set to 16 pixels. To smooth the strain values, the interval value was set to 4 . With this configuration, the correlation results can provide the in-plane initial and current positions and the strains for each subset at different times. 


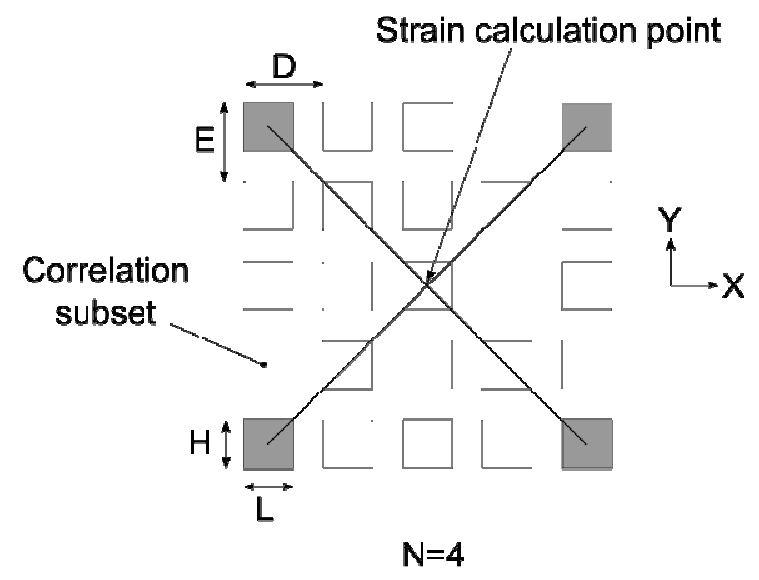

Fig. 7 Subset dimensions and calculation strain model used in DIC technique

Fig. 8 shows an image of a specimen in the initial state. The central square area 1 (highlighted in blue) of approximately $25 \times 25 \mathrm{~mm}^{2}$ was selected for two specimens, leading to a total number of about 1600 calculation points. Major strain $\varepsilon_{1}$, minor strain $\varepsilon_{2}$ and the strain path ratio, defined by the ratio $\varepsilon_{2} / \varepsilon_{1}$, were output at these points and analyzed just before rupture took place, at time $\mathrm{t}=6.0 \mathrm{~s}$ for AA5086 and $\mathrm{t}=3.240 \mathrm{~s}$ for DP980.

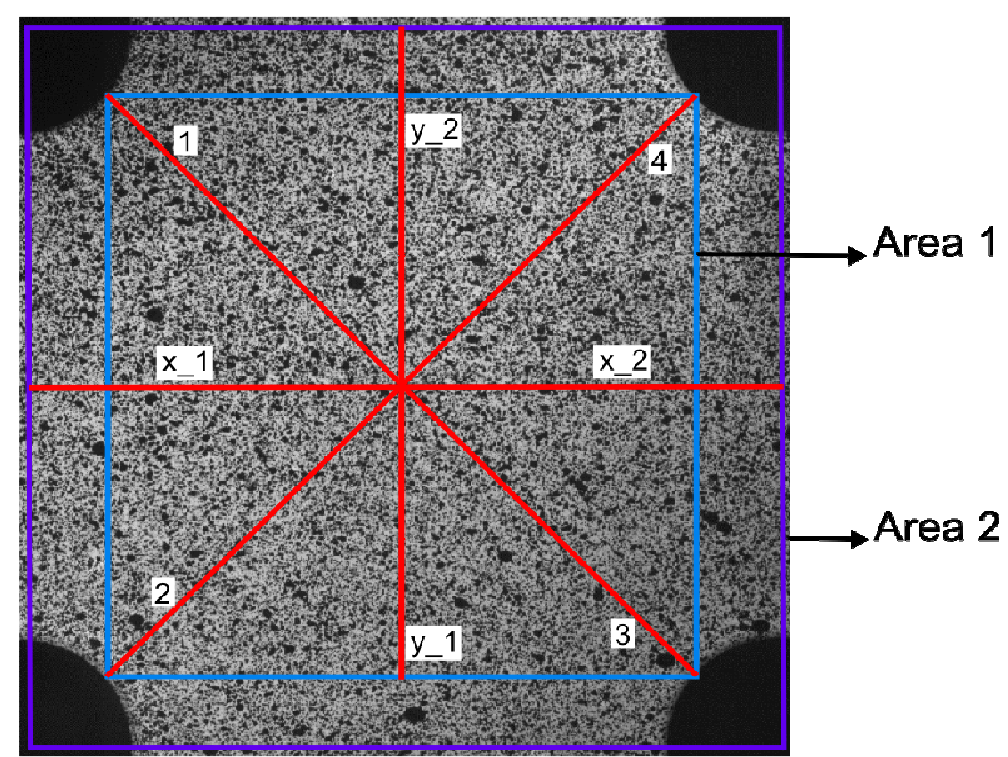

Fig. 8 Analysis areas in the central part of the cruciform specimen and visualization of specified paths. $1,2,3,4$ are the diagonal profiles, $x \_1, x \_2$ the longitudinal ones and $\mathbf{y} \_1, y_{\_} 2$ the transverse ones. The inner blue square has a side of $25 \mathrm{~mm}$ 
The strain field in the central area is presented in Fig. 9 for both specimens. Similar distributions for the two specimens have been observed. However, the maximum strain level of DP980 is much lower than AA5086. Fig. 9(a) and (b) shows the major strain distribution. The strain increases from the center to the edge with a lowest value in the center around 0.024 for AA5086 and 0.01 for DP980, up to the largest value at about 0.11 and 0.036 respectively. Fig. 9(c) and (d) gives the minor strain distribution. It decreases from about 0.024 for AA5086 and 0.0098 for DP980 at the center down to around -0.019 and -0.007 at the edge, respectively. Fig. 9(e) and (f) presents the strain path ratio distribution. There is nearly an equi-biaxial strain state (about 0.90 and 0.95 respectively) for both specimens in the central area. It then changes gradually along the diagonal direction to nearly uniaxial tensile strain state (about -0.17 for both specimens) near the corner. The designed cruciform specimen presents therefore different levels of strain in the central gauge area, which is an interesting feature to be used in the material parameter identification. It can be emphasized that a rather low maximum strain was reached for the biaxial stress state corresponding to the fact that a constant thickness was used. Indeed, higher strains (up to rupture) were only obtained by reducing locally the thickness in the central area [35]. 


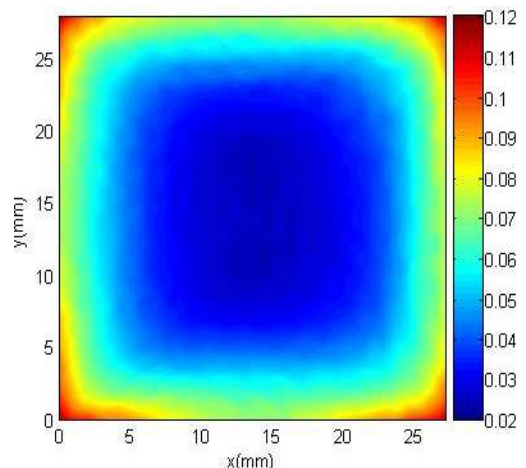

(a)

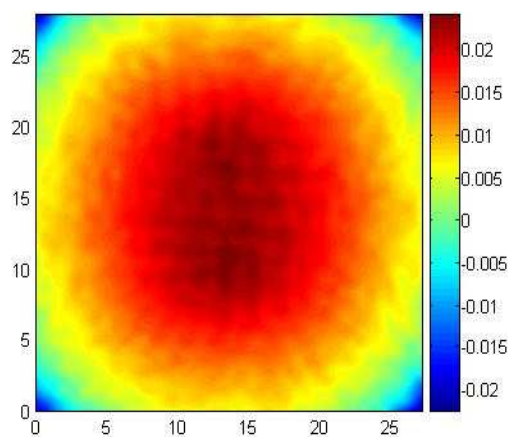

(c)

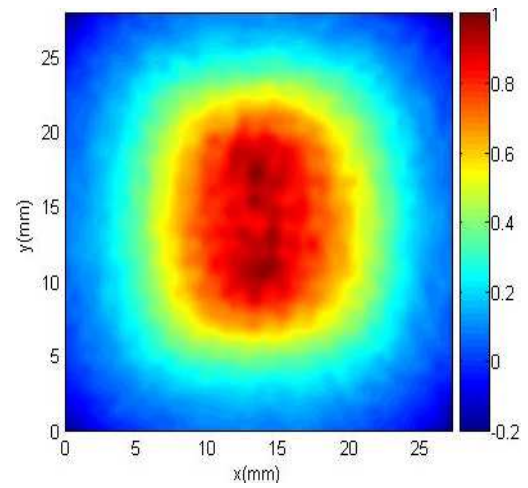

(e)

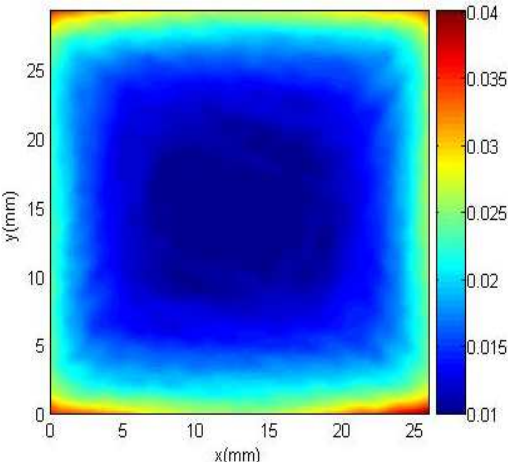

(b)

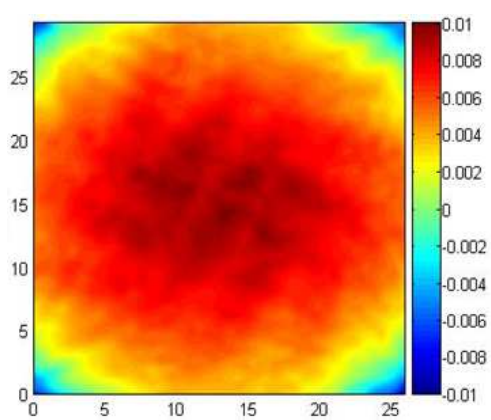

(d)

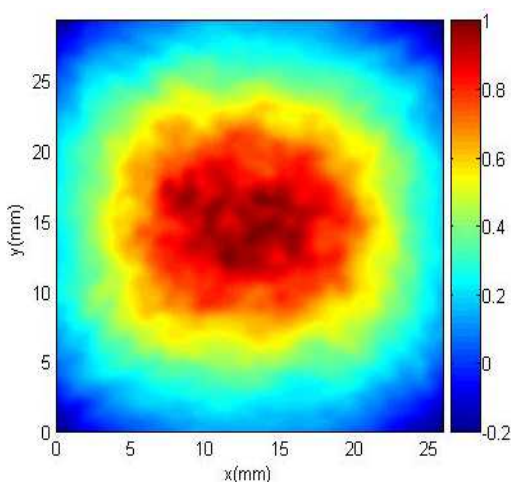

(f)

Fig. 9 Major and minor strains and strain path ratios in the central area for AA5086 [(a), (c), (e)] and DP980 [(b), (d), (f)]

The strain field data $\left(\varepsilon_{1}, \varepsilon_{2}\right.$ and $\left.\varepsilon_{2} / \varepsilon_{1}\right)$ was then output along the selected directions given in Fig. 8, in order to have a quantitative view on the evolution.

\subsection{Principal strains along diagonal profiles}

Fig. 10 presents the major and minor strains. Each diagonal direction being at $45^{\circ}$ to both $\mathrm{RD}$ and TD, the lengths of these four directions are all equal. When comparing the four profiles (1 to 4 ) 
for each specimen and whatever the material, a slight discrepancy is recorded near the free edge of the sample, the maximum relative gap being about $10 \%$ for the major strain and $5 \%$ for the minor strain. The values are about 0.026 and 0.024 for AA50816 at the center for major and minor strains respectively, but only 0.01 for both major and minor strains for DP980. About $10 \%$ of difference between the major and minor strains is recorded in the center for AA5086 whereas no difference is noted for DP980, which reflects the stronger anisotropy of the aluminium alloy compared to DP steel.

The major strain then increases with the distance from the center to the edge for both materials. It reaches up to about 0.11 for AA5086 and 0.034 for DP980. On the contrary, the minor strain decreases continuously along the axis. The average value at the corner is about -0.015 for AA5086, -0.006 for DP980. It can be noted that, for DP980, though the measured strain level is low, the dispersion is rather low over the 4 diagonal profiles.

An average value, both for minor and major strains, was then calculated over the four profiles. The evolution of the strain path ratio was figured out with the averaged principal strains and is presented in Fig. 11. The evolution is quite similar for both materials, with a continuous decrease of the strain path ratio from the center to the free edge, though some slight differences exist: the maximum value reached in the center is higher for DP980 than for AA5086, with a sharper decrease in-between 4 and $16 \mathrm{~mm}$ for AA5086 than for DP steel. The two curves then converge toward a same one. It can be clearly seen that the strain state varies from nearly equi-biaxial tensile strain state (about 0.87 for AA5086 and 0.92 for DP980) in the specimen center to a state (about -0.15 and -0.17 respectively) between uniaxial tension $(-0.3)$ and plane strain tension $(0)$. 


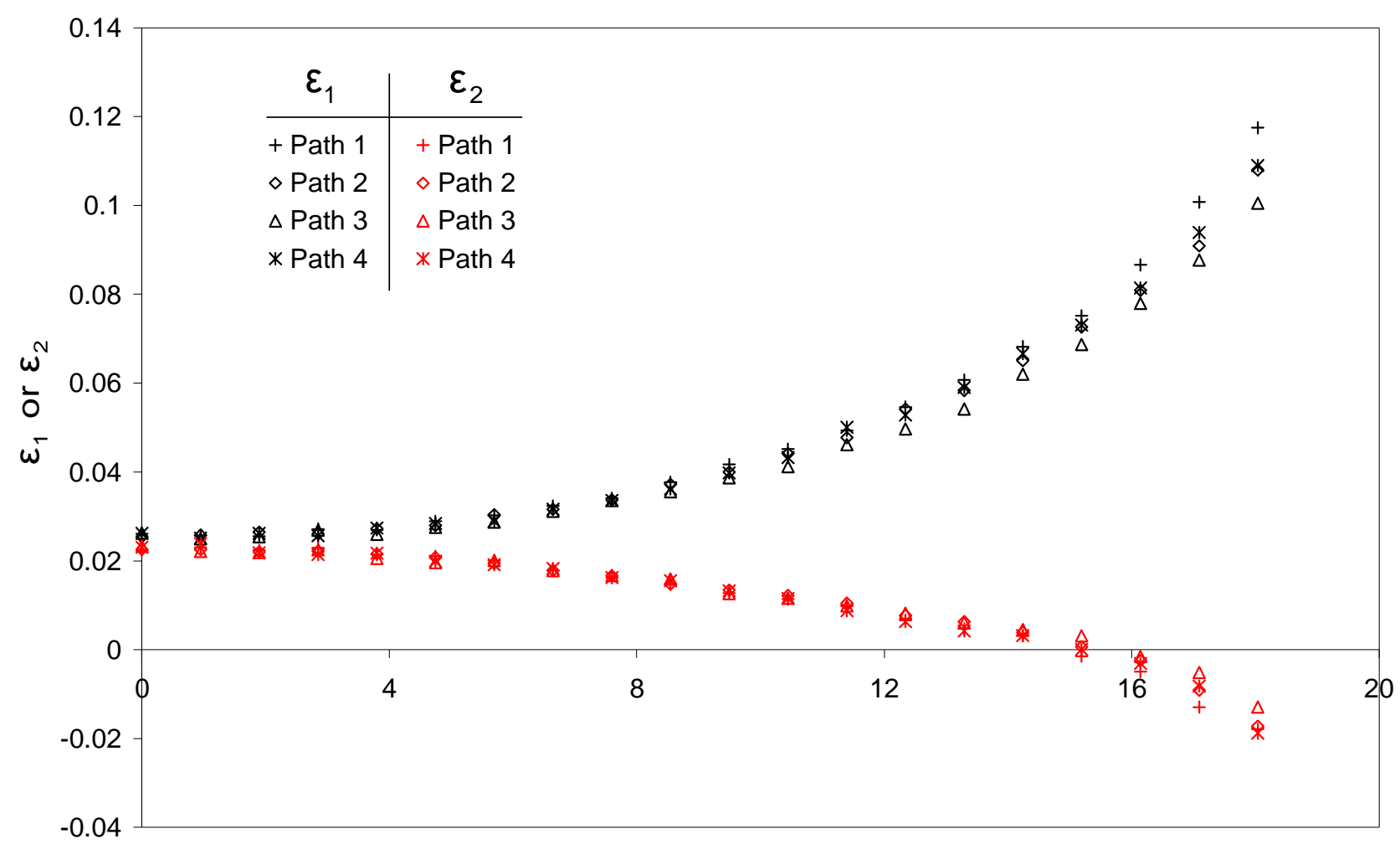

Distance from centre $(\mathrm{mm})$

(a)

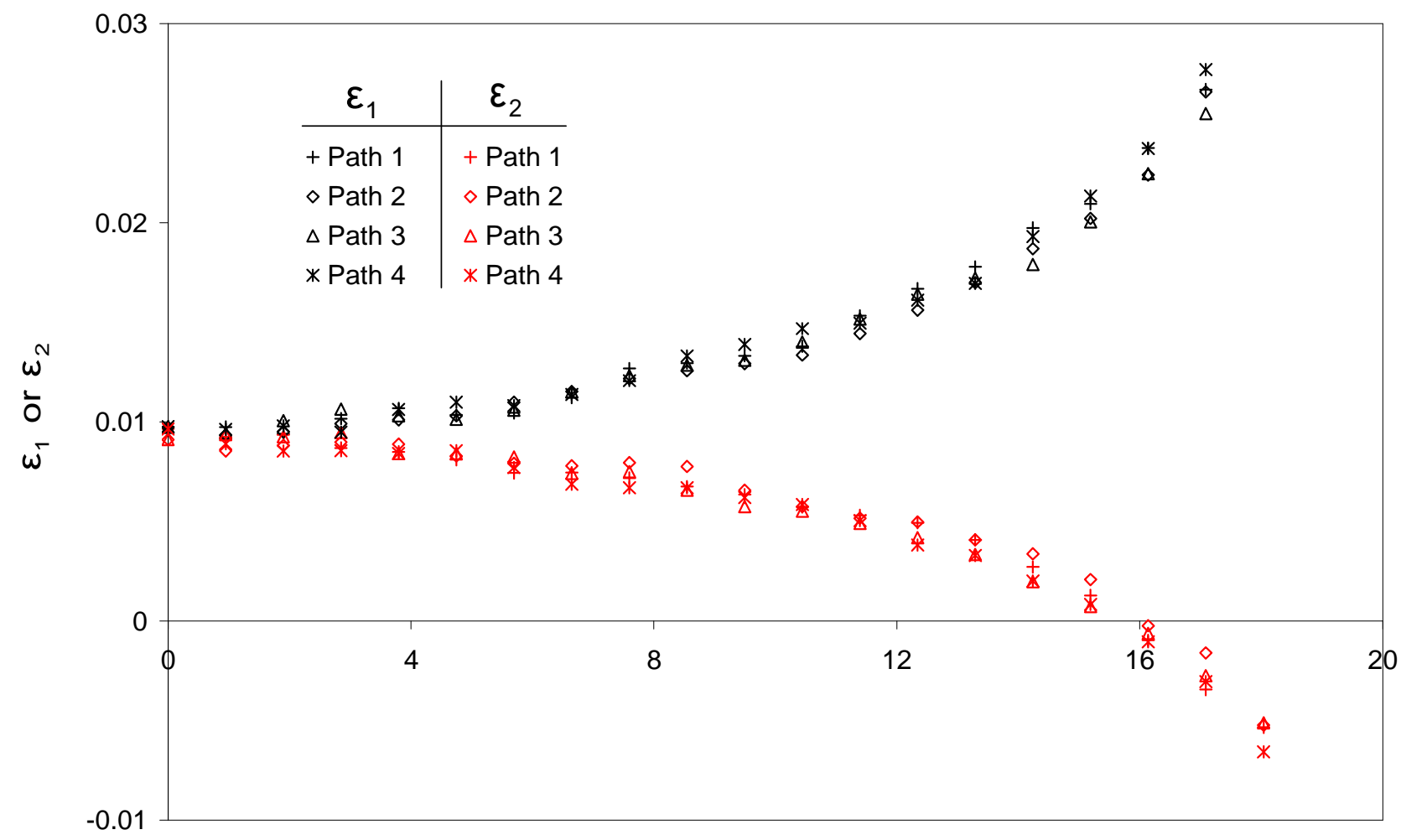

Distance from centre $(\mathrm{mm})$

(b)

Fig. 10 Principal strains along four diagonal profiles: (a) AA5086 - (b) DP980 


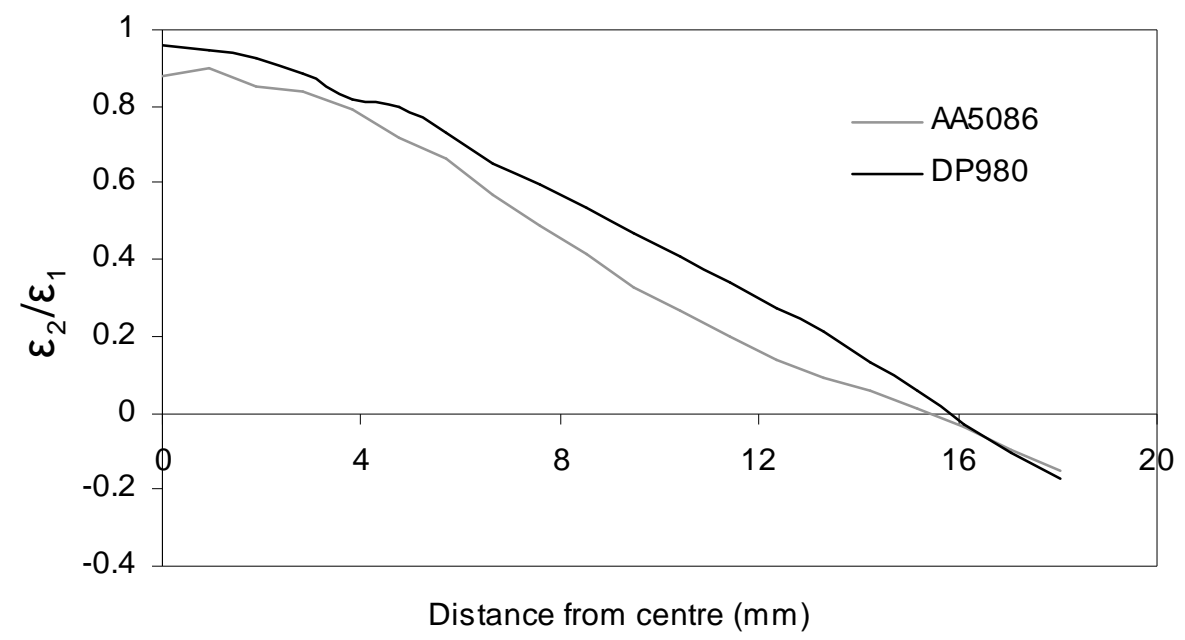

Fig. 11 Strain path ratio along diagonal path

\subsection{Principal strains along longitudinal and transverse directions}

A second square area (area 2, highlighted in purple in Fig. 8) of approximately $32 \times 32 \mathrm{~mm}^{2}$ (leading to 2500 calculation points) was also selected to output the principal strains along longitudinal and transverse directions. Rupture took place on the arm corresponding to profile $\mathrm{x} \_2$ for all specimens.

Fig. 12 presents the major and minor strains and the strain path ratio along longitudinal and transverse profiles for AA5086 (Fig. 12(a)) and DP980 (Fig. 12(b)). Concerning AA5086, the evolution of the major strain $\varepsilon_{1}$ along the four paths is rather similar up to a distance of $14 \mathrm{~mm}$ from the center. Between the profiles along rolling and transverse directions, a slight gap is recorded: the values along rolling direction are a little higher than the ones along transverse direction from $4 \mathrm{~mm}$ to $12 \mathrm{~mm}$. Values are close to each other for two profiles corresponding to the same direction. After $14 \mathrm{~mm}$ from the center, the difference between each profile becomes more and more significant since necking has taken place in the arm along profile $\mathrm{x} \_2$ just before the rupture. The evolution of the minor strain $\varepsilon_{2}$ along direction y is slightly higher than the one along direction $\mathrm{x}$. It can be seen that a maximum value along transverse direction is recorded, around 4 $\mathrm{mm}$ from the specimen center. Generally speaking, the minor strain along both directions 
decreases from 0.021 in the center down to around 0 at the beginning of the arm.

The obtained values for DP980 are much lower than the ones for AA5086, ranging from 0.01 in the center up to a maximum of 0.06 . The values of the major strain along the four profiles are close to each other in the specimen center and below $12 \mathrm{~mm}$. However, above $12 \mathrm{~mm}$, the difference between longitudinal and transverse directions becomes more and more significant, due to necking. Necking is evidenced along the longitudinal direction, especially profile $\mathrm{x} \_2$ with a high increase of the strain, whereas a stable increase at a lower rate can be noticed for the other profiles. Dispersions can be noticed for the minor strain, since the very low value can be influenced by the strain measure dispersion. However there is no significantly difference between the four profiles. The minor strain decreases from 0.009 in the center down to around 0.003 at the beginning of the arm.

The strain path ratio for the four profiles is also presented in Fig. 12. It can be seen that, for AA5086, the values are close for the two profiles along the same direction. However, there is a significant gap between rolling and transverse directions, with an increase of the ratio up to 1 at a distance of $4 \mathrm{~mm}$ from the specimen center, along the transverse direction. The strain state along these profiles varies from nearly equi-biaxial tensile strain state to a state of plane strain. It is unfortunate that the strain path corresponding to uniaxial tensile strain state could not be captured in this experiment. In future works, tests should be performed with a larger camera view both for the central area and the specimen arms, to enlarge the measurement area. However, a larger view will also decrease the accuracy of the strain measure in the central gauge area, which can be a significant drawback due to the low strains measured.

On the contrary, for DP980, it can be seen that the strain path ratio along the two directions are rather close to each other. And the sensitive increase along transverse direction recorded for AA5086 is not noticed for DP980. However, there is a certain discrepancy, especially for a distance in-between 4 and $8 \mathrm{~mm}$ from the specimen center. In this area, the variation range can 
reach $25 \%$. However, the strain state variation range is similar to the one of AA5086. Indeed, it varies from nearly equi-biaxial tensile strain state to a nearly plane strain state. The minimum value is about 0.07 , which remains positive.

\subsection{Principal strains along diagonal paths for DP980 far from necking}

Strain evolution along longitudinal and transverse directions was influenced significantly by necking, in particular for DP steel. Therefore, to check this influence, an analysis at a smaller time step, far away from necking, was conducted. The strain field in the central gauge area at $\mathrm{t}=2 \mathrm{~s}$ was then analyzed, but only for DP980. The maximum and minimum principal strains at $\mathrm{t}=2 \mathrm{~s}$ along four diagonal profiles are presented in Fig. 13. Comparing with the strain just before rupture (Fig. 10(b)), a lower strain level and a more significant discrepancy were recorded. Near the free edge of the sample, the maximum relative gap is about $28 \%$ for the major strain and $50 \%$ for the minor strain for the four profiles. The difference between major and minor strains at the center is about $12 \%$, which is higher than the one at $\mathrm{t}=3.232 \mathrm{~s}$. Near the free edge, an average value about 0.02 is obtained for the major strain, while -0.004 is obtained for the minor strain. 

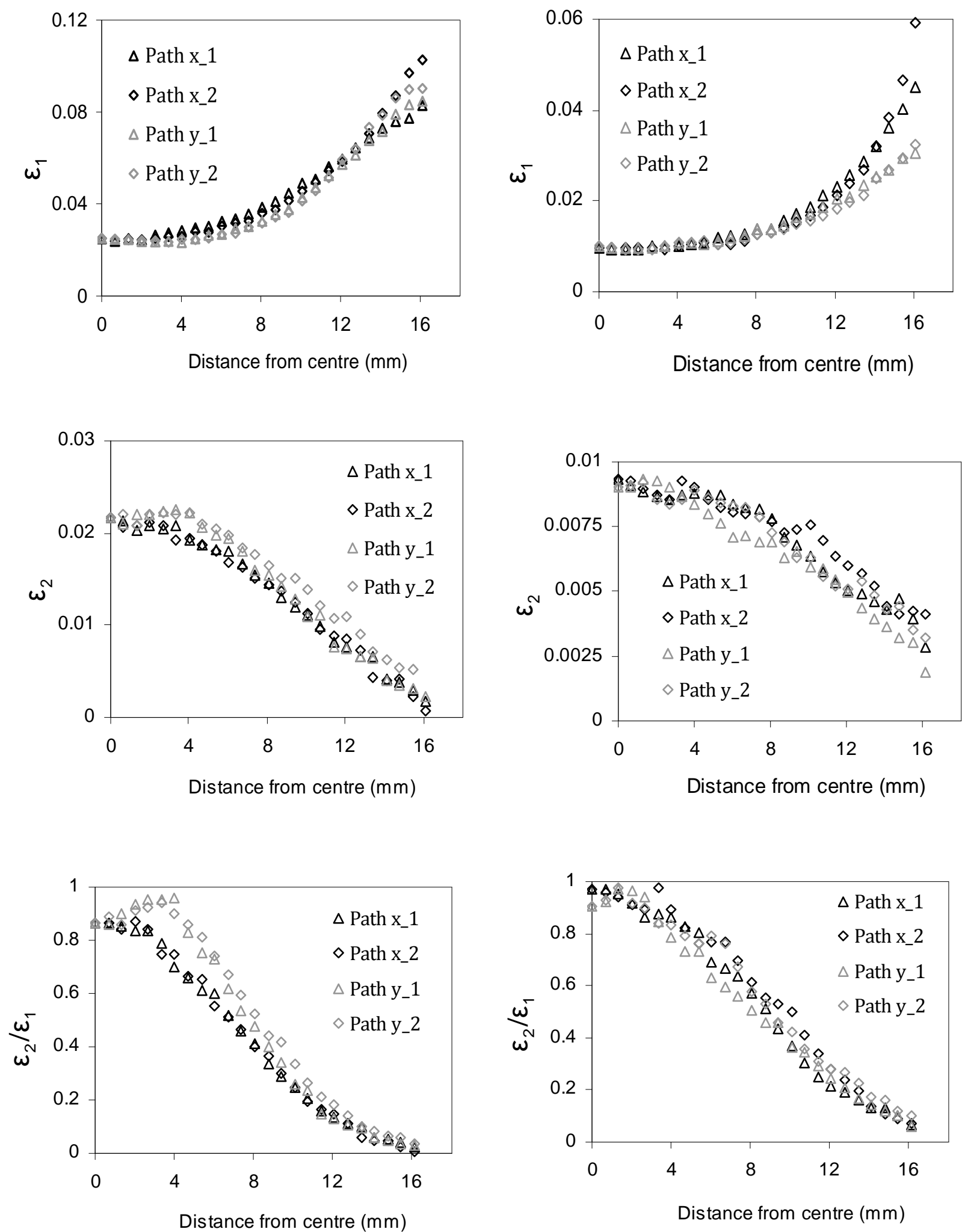

(a) AA5086

(b) DP980

Fig. 12 Principal strains and strain path ratios along longitudinal and transverse profiles for both materials 


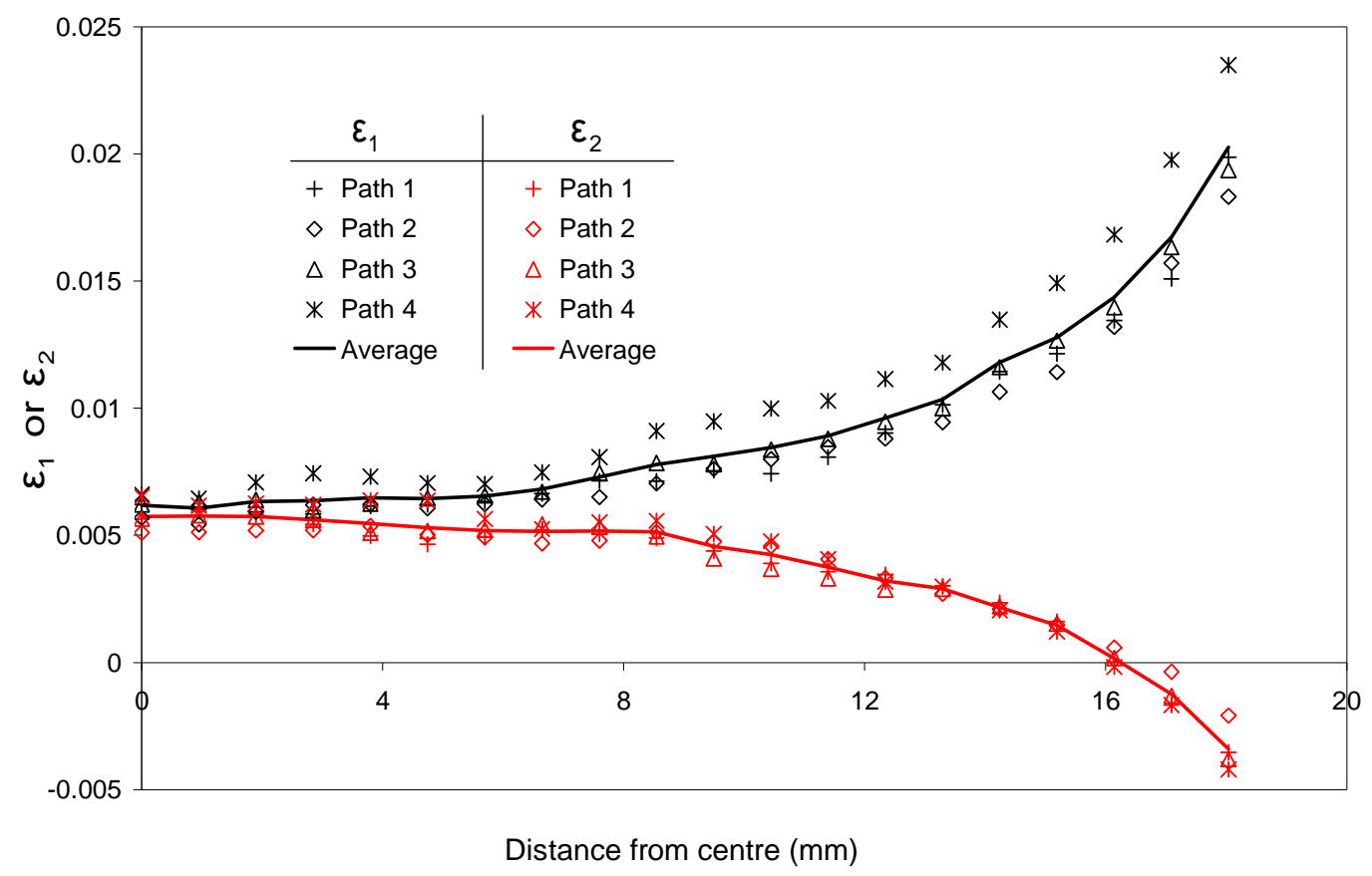

Fig. 13 Principal strain along the four diagonal profiles and average value for DP980 at $\mathrm{t}=2 \mathrm{~s}$

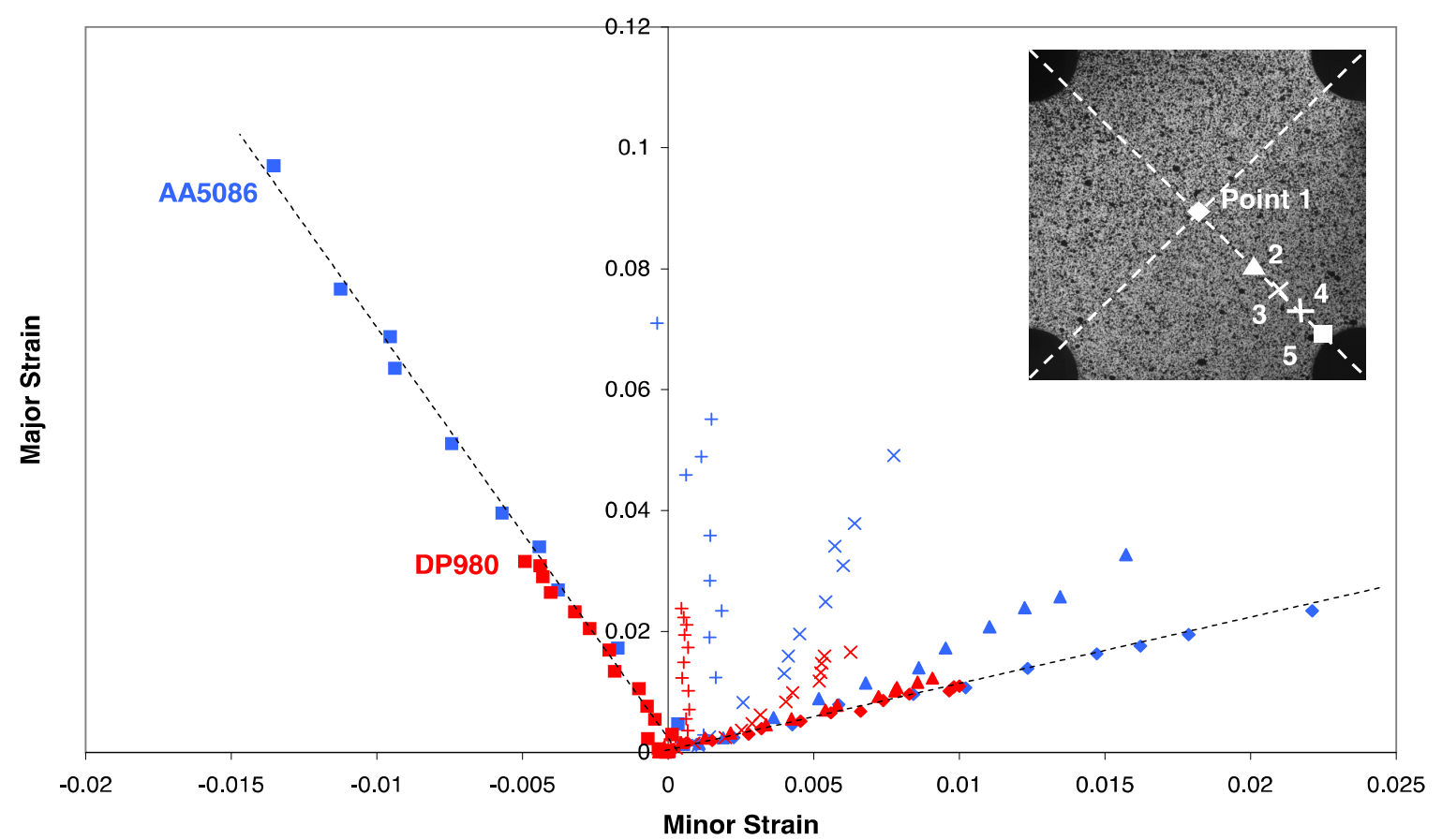

Fig. 14 Strain paths for different points on a diagonal profile for AA5086 (in blue) and DP980 (in red) 


\subsection{Discussion}

Two main advantages of the biaxial tensile test have been evidenced so far: the strain field exhibits a certain sensitivity to the material anisotropy and also a wide range of strain paths can be investigated. Indeed, considering the evolution of the strain path ratio along longitudinal and transverse directions, it was shown that a non-monotonous evolution occurred in the transverse direction for AA5086. From the center up to a distance of $4 \mathrm{~mm}$, the major strain tends to slightly decrease after the initial value whereas the minor strain increases, leading to a significant increase of the strain path ratio from 0.8 to 0.95 . This specificity was not observed for DP980 and it may come from the material anisotropy. The origin of such an evolution will be checked later with the help of numerical simulation.

Secondly, Fig. 14 exhibits the evolution of the major strain as a function of the minor strain for several material points along the diagonal direction. This reflects the temporal evolution of the strain path ratio and it can be seen that a rather linear evolution is imposed during the biaxial tensile test for points labeled 1,2,4 and 5. This suggests that the information given by a strain field at a fixed time is rich enough and adding other times leads to mainly an increase of the strain level but does not bring other strain path. For point 3, the strain path is no longer linear, with a beginning close to biaxial tension and then an intermediate strain state between biaxial and plane strain tension. Concerning point 5, located near the free edge, the strain state seems more dependent on the boundary conditions then on the material anisotropy, as is the case for a uniaxial tension, because a rather similar slope is noticed for the two materials.

Due to the sensitivity to material anisotropy and the vast range of strain paths, a material parameter identification was developed, considering the average values over the four profiles along the diagonal direction, which were less sensitive to the necking occurring before rupture and exhibit less dispersion. 


\section{Numerical strain field predictions}

Bron and Besson anisotropic yield function, associated to isotropic hardening, was implemented as a user subroutine in the finite element code. Out of comparison's sake, Hill 1948 yield criterion was also used. The equations of these yield criteria are recalled below using the frame $(\overrightarrow{1}, \overrightarrow{2}, \overrightarrow{3})$, where the directions correspond to the rolling direction (RD), transverse direction (TD) and normal direction (ND) respectively.

\subsection{Material models}

\subsubsection{Bron and Besson yield model}

Bron and Besson proposed a yield function involving 16 parameters under the form [5]:

$$
\psi\left(\sigma_{\mathrm{ij}}\right)=\left(\sum_{\mathrm{k}=1}^{2} \alpha^{\mathrm{k}}\left(\bar{\sigma}^{\mathrm{k}}\right)^{\mathrm{a}}\right)^{1 / \mathrm{a}}
$$

$\alpha^{\mathrm{k}}, \mathrm{k}=1,2$, are positive coefficients, the sum of which is equal to $1 . \sigma_{\mathrm{ij}}$ are the components of Cauchy stress tensor. Plastic yielding occurs when $\psi=\bar{\sigma}=Y_{0}$, where $\bar{\sigma}$ is the equivalent stress and $Y_{0}$ a reference yield stress characteristics of the material. It should be emphasized that $Y_{0}$ is not equal to the uniaxial yield stress in the rolling direction. $\bar{\sigma}^{\mathrm{k}}$ are expressed in the form:

$$
\begin{aligned}
& \bar{\sigma}^{1}=\left(\frac{1}{2}\left(\left|S_{2}^{1}-S_{3}^{1}\right|^{b_{1}}+\left|S_{3}^{1}-S_{1}^{1}\right|^{b_{1}}+\left|S_{2}^{1}-S_{1}^{1}\right|^{b_{1}}\right)\right)^{1 / b_{1}} \\
& \bar{\sigma}^{2}=\left(\frac{3 b_{2}}{2^{b_{2}}+2}\left(\left|S_{1}^{2}\right|^{b_{2}}+\left|S_{2}^{2}\right|^{b_{2}}+\left|S_{3}^{2}\right|^{b_{2}}\right)\right)^{1 / b_{2}}
\end{aligned}
$$

$\mathrm{a}, \mathrm{b}_{1}, \mathrm{~b}_{2}$ and $\alpha^{1}\left(\alpha^{2}=1-\alpha^{1}\right)$ are four isotropic parameters which define the shape of the yield surface.

$S_{i}^{k}$ are the principal values of the transformed stress deviators $s_{i j}^{\prime k}$ defined by: 
$\mathrm{s}_{\mathrm{ij}}^{\prime \mathrm{k}}=\mathrm{L}^{\mathrm{k}} \sigma_{\mathrm{ij}}$ with

$$
\mathrm{L}^{\mathrm{k}}=\left(\begin{array}{cccccc}
\frac{\mathrm{c}_{2}^{\mathrm{k}}+\mathrm{c}_{3}^{\mathrm{k}}}{3} & -\frac{\mathrm{c}_{3}^{\mathrm{k}}}{3} & -\frac{\mathrm{c}_{2}^{\mathrm{k}}}{3} & 0 & 0 & 0 \\
-\frac{\mathrm{c}_{3}^{\mathrm{k}}}{3} & \frac{\mathrm{c}_{1}^{\mathrm{k}}+\mathrm{c}_{3}^{\mathrm{k}}}{3} & -\frac{\mathrm{c}_{1}^{\mathrm{k}}}{3} & 0 & 0 & 0 \\
-\frac{\mathrm{c}_{2}^{\mathrm{k}}}{3} & -\frac{\mathrm{c}_{1}^{\mathrm{k}}}{3} & \frac{\mathrm{c}_{1}^{\mathrm{k}}+\mathrm{c}_{2}^{\mathrm{k}}}{3} & 0 & 0 & 0 \\
0 & 0 & 0 & \mathrm{c}_{4}^{\mathrm{k}} & 0 & 0 \\
0 & 0 & 0 & 0 & \mathrm{c}_{5}^{\mathrm{k}} & 0 \\
0 & 0 & 0 & 0 & 0 & \mathrm{c}_{6}^{\mathrm{k}}
\end{array}\right)
$$

where $\mathrm{c}_{\mathrm{m}}^{\mathrm{k}}$ are 12 parameters which are related to the anisotropy of the material. In plane stress condition, the anisotropic parameter number reduces to 8 with $c_{5}^{k}=c_{6}^{k}=1$. So there are a total of 13 parameters to be identified. Bron and Besson yield model will be called B\&B yield model in the following.

\subsubsection{Hill 1948 yield model}

Hill 1948 orthotropic yield function is written in the following form [1]:

$$
\psi_{\mathrm{H}}=\sqrt{\mathrm{F}\left(\sigma_{22}-\sigma_{33}\right)^{2}+\mathrm{G}\left(\sigma_{33}-\sigma_{11}\right)^{2}+\mathrm{H}\left(\sigma_{11}-\sigma_{22}\right)^{2}+2 \mathrm{~L} \sigma_{23}^{2}+2 \mathrm{M} \sigma_{13}^{2}+2 \mathrm{~N} \sigma_{12}^{2}}
$$

where $\psi_{\mathrm{H}}$ denotes the yield function. Plastic yielding occurs when $\psi_{\mathrm{H}}=\bar{\sigma}=\mathrm{Y}_{0} . \mathrm{F}, \mathrm{G}, \mathrm{H}, \mathrm{L}, \mathrm{M}$ and $\mathrm{N}$ are material parameters. When the condition $\mathrm{G}+\mathrm{H}=1$ is imposed, $\mathrm{Y}_{0}$ is the uniaxial yield stress along the rolling direction. Then, with plane stress conditions $\left(\sigma_{33}=\sigma_{13}=\sigma_{23}=0\right)$, three independent anisotropic parameters $\mathrm{F}, \mathrm{G}$ and $\mathrm{N}$ have to be identified. In this work, they were calculated from the anisotropic coefficients.

\subsubsection{Strain hardening law}

Hardening of the material is modeled with isotropic hardening identified from a tensile test in the rolling direction. From the tensile test data in the rolling direction, and assuming isotropy, the 
equivalent plastic strain was calculated and Cauchy stress versus equivalent plastic strain curve was fitted. For aluminium alloy AA5086, a Voce equation given by $\sigma_{0}=\sigma_{\mathrm{s}}+\mathrm{Q}\left(1-\exp \left(-\mathrm{B} \bar{\varepsilon}^{\mathrm{p}}\right)\right)$, with $\sigma_{\mathrm{s}}=146 \mathrm{MPa}, \mathrm{Q}=217.6 \mathrm{MPa}$ and $\mathrm{B}=10.9$ is adopted. These parameters were determined from tensile data and were kept constant throughout the study. From the relation $\bar{\sigma}=\mathrm{Y}_{0}$, it comes that the hardening law introduced in the finite element code is written as:

$$
\bar{\sigma}=\psi\left(\frac{\left[\sigma_{\mathrm{ij}}\right]_{\mathrm{UT}}}{\sigma_{0}}, \mathrm{a}, \mathrm{b}_{1}, \mathrm{~b}_{2}, \mathrm{a}^{1}, \mathrm{c}_{\mathrm{m}}^{\mathrm{k}}\right)\left(\sigma_{\mathrm{s}}+\mathrm{Q}\left(1-\exp \left(-\mathrm{B} \bar{\varepsilon}^{\mathrm{p}}\right)\right)\right)
$$

where the first term in the right-hand side part of eq. (5) depends only on the stress tensor for uniaxial tension in RD (only one non-zero component) normalized by the yield stress in RD and on the parameter set for the anisotropic yield criterion.

For the steel DP980, the hardening law is described by a combined equation based on Swift and Voce formulations as presented in eq. (6).

$$
\sigma_{0}=\alpha\left[\mathrm{K}\left(\bar{\varepsilon}^{\mathrm{p}}+\varepsilon_{0}\right)^{\mathrm{n}}+\mathrm{H} \bar{\varepsilon}^{\mathrm{p}}\right]+(1-\alpha)\left(\sigma_{\mathrm{s}}+\mathrm{Q} \sqrt{1-\exp \left(-\mathrm{B} \bar{\varepsilon}^{\mathrm{p}}\right)}\right) \text { with } \varepsilon_{0}=\left(\frac{\sigma_{\mathrm{s}}}{\mathrm{K}}\right)^{\frac{1}{\mathrm{n}}}
$$

Parameters values are: $\alpha=0.5 ; \mathrm{K}=1600 ; \sigma_{\mathrm{s}}=449.2 \mathrm{MPa} ; \mathrm{H}=150 \mathrm{MPa} ; \mathrm{n}=0.09 ; \mathrm{Q}=500 \mathrm{MPa} ; \mathrm{B}=120$.

\subsection{Finite element model of the biaxial tensile test}

Finite element (FE) simulations of the biaxial test were carried out with the commercial software ABAQUS, with the implicit solver. The anisotropic behavior of the material was modeled by Bron and Besson yield function implemented through a user subroutine [13, 33].

The boundary conditions of numerical simulation of the biaxial test are shown in Fig. 15. Due to the symmetry of the problem, only a quarter of the specimen was modeled. The load values $\mathrm{F}_{\mathrm{X}}$ and $\mathrm{F}_{\mathrm{Y}}$ derived from the experiments were used as input to the numerical simulation and due to 
the symmetry, $F_{X} / 2$ and $F_{Y} / 2$ were imposed on the two arms. Four node shell elements were used for the mesh. A minimum element size of the mesh was fixed at $1 \mathrm{~mm}$, insuring the calculation accuracy and also a minimum simulation time. Influence of the mesh size was investigated, in particular its influence on the major and minor strain distributions, and stable predictions were obtained with the selected mesh. The computational time is about ten minutes (processor i7-640M, 2.8 GHz with 4Go RAM) with these conditions.

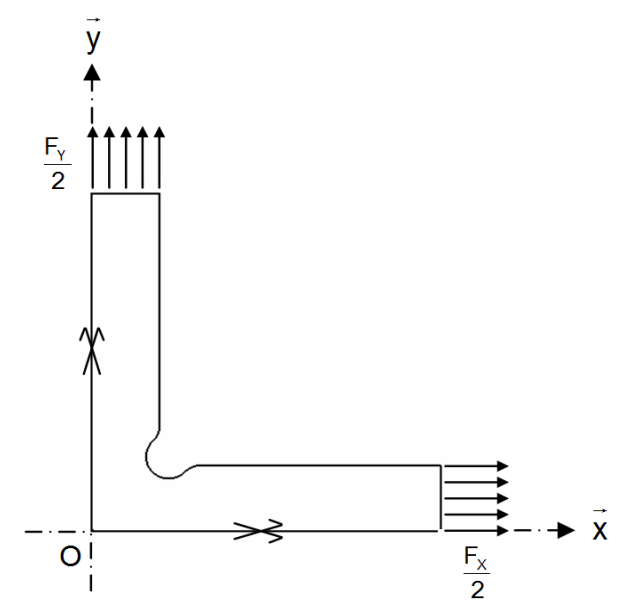

\section{Fig. 15 Numerical model with imposed force}

\subsection{Methodology of identification process}

In inverse approaches, different experimental quantities have been successfully used like displacements [48], strains [49], velocities or forces. Rigid body motions (RBM) strongly affect the experimental measured displacements. With the biaxial tensile test, the cruciform specimen is loaded by four independent actuators and it is very difficult to guarantee a perfect synchronization between the different axes. The rigid body motion induces a slight displacement of the center and an in-plane rotation of the specimen. Due to the small displacements measured in the center of the specimen during the test, the part of rigid body displacements is not insignificant. This problem is well known by the community and for instance, the use of relative displacements is the best way to compensate the RBM. In our case, it is very difficult to calculate precisely the relative displacements since a slight out of synchronization can lead to a small time lag between the two 
axes and the start of loading is not exactly the same for all the material points. Another approach [50] consists in prescribing the measured boundary conditions to the finite element model and use relative displacement to formulate the cost-function and thus cancel the influence of RBM. In this work, displacement fields are sufficiently unnoised to allow a proper strain calculation and thus define a stable cost-function. Cost function is then formulated from strain fields obtained through the space-derivative of the displacement fields. Initial mesh size of strain calculation points by DIC technique is about $0.7 \mathrm{~mm}$ and as explained above, a global size of $1 \mathrm{~mm}$ has been chosen for the FE model mesh.

A cost function was defined to calculate the difference between the experimental and numerical principal strains:

$$
\delta\left(\mathrm{Y}_{0}, \mathrm{a}, \mathrm{b}_{1}, \mathrm{~b}_{2}, \alpha_{1}, \mathrm{c}_{\mathrm{m}}^{\mathrm{k}}\right)=\frac{\sum_{\mathrm{i}=1}^{\mathrm{p}}\left(\varepsilon_{1}^{\text {exp } \_\mathrm{i}}-\varepsilon_{1}^{\text {num } \_\mathrm{i}}\right)^{2}}{\sum_{\mathrm{i}=1}^{\mathrm{p}}\left(\varepsilon_{1}^{\text {exp } \_\mathrm{i}}\right)^{2}}+\frac{\sum_{\mathrm{i}=1}^{\mathrm{p}}\left(\varepsilon_{2}^{\text {exp } \_\mathrm{i}}-\varepsilon_{2}^{\text {num } \_\mathrm{i}}\right)^{2}}{\sum_{\mathrm{i}=1}^{\mathrm{p}}\left(\varepsilon_{2}^{\text {exp } \_\mathrm{i}}\right)^{2}}
$$

where $\mathrm{p}$ corresponds to the number of calculation points used along the diagonal path, $\varepsilon_{1}^{\text {exp } \_ \text {i }}$ and $\varepsilon_{2}^{\text {exp_i }}(i=1, p)$ are the experimental values for the major and minor strains respectively; $\varepsilon_{1}^{\text {num } \_i}$ and $\varepsilon_{2}^{\text {num } \mathrm{i}}(\mathrm{i}=1, \mathrm{p})$ are the numerical principal strains output from the numerical simulation and interpolated with Piecewise Cubic Hermite Interpolating Polynomial [45], to calculate their value at the same location as the experimental values. Indeed, as shown in Fig. 16, for a given distance from the center coming from the experiments $d^{\text {exp } \_ \text {, }}$, the corresponding numerical principal strains $\varepsilon_{1}^{\text {num } \_}$and $\varepsilon_{2}^{\text {num } i}$ are interpolated from the principal values at nodes $j$ and $j+1$, which are along diagonal direction. 


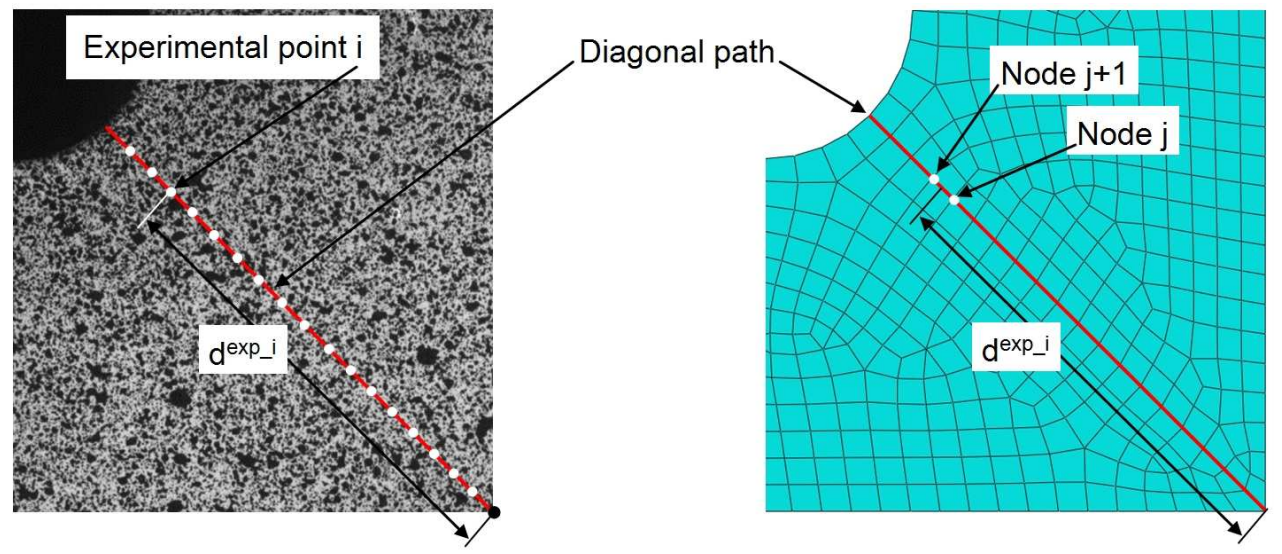

\section{Fig. 16 Interpolation of the numerical strain field to calculate values at the same point as the experiments}

The identification process with biaxial test data was realized with the software modeFRONTIER ${ }^{\circledR}$ [46]. It was coupled with software Abaqus and Matlab (for the interpolation and the calculation of the cost function) for this optimization.

The optimization process is presented as a flowchart in Fig. 17. The major task lied in the optimization of the material parameters with the recourse to a finite element simulation to minimize the cost function.

Firstly, the variation range of parameters was determined. The central values and their variation range for each parameter are given in Table 2. For the reference yield stress $\mathrm{Y}_{0}$, the variation range was set to be from $0.8 \sigma_{0}$ to $1.2 \sigma_{0}$.

Table 2 Central values and variation ranges (in brackets) for each parameter

\begin{tabular}{cccccc}
\hline$\alpha_{1}$ & $\mathrm{a}$ & $\mathrm{b}_{1}$ & $\mathrm{~b}_{2}$ & $\mathrm{c}_{1}^{1}$ & $\mathrm{c}_{2}^{1}$ \\
\hline $0.5(0.1 \sim 0.9)$ & $6(0 \sim 12)$ & $10(0 \sim 20)$ & $10(0 \sim 20)$ & $0.5(-1.2 \sim 2.2)$ & $0.5(-1.2 \sim 2.2)$ \\
\hline $\mathrm{c}_{3}^{1}$ & $\mathrm{c}_{4}^{1}$ & $\mathrm{c}_{1}^{2}$ & $\mathrm{c}_{2}^{2}$ & $\mathrm{c}_{3}^{2}$ & $\mathrm{c}_{4}^{2}$ \\
\hline $0.5(-1.2 \sim 2.2)$ & $0.5(-1.2 \sim 2.2)$ & $0.5(-1.2 \sim 2.2)$ & $0.5(-1.2 \sim 2.2)$ & $0.5(-1.2 \sim 2.2)$ & $0.5(-1.2 \sim 2.2)$ \\
\hline
\end{tabular}


The optimization algorithm Simplex [47] was preferred in the identification process. Like hill climbing algorithms, the Simplex method may not converge to the global minimum and can stop at local optima. To be sure that the global minimum was found, several optimizations were launched with various initial sets of parameters. The Simplex method presents the advantage of using $n+1$ vectors (with $\mathrm{n}$ the number of parameters) and then facilitates the search of the global minimum in the n-dimensional space. The use of a first-order optimization algorithm with only one initial vector requires more tests than Simplex with different initial sets to cover the n-dimensional space. Nevertheless, the convergence is less efficient with Simplex method than for many algorithms when the number of parameters is high. A best approach could consist in applying a hybrid method by using for example an evolutionary algorithm to localize approximately the global minimum of the cost function and then converge efficiently with a first-order optimization algorithm.

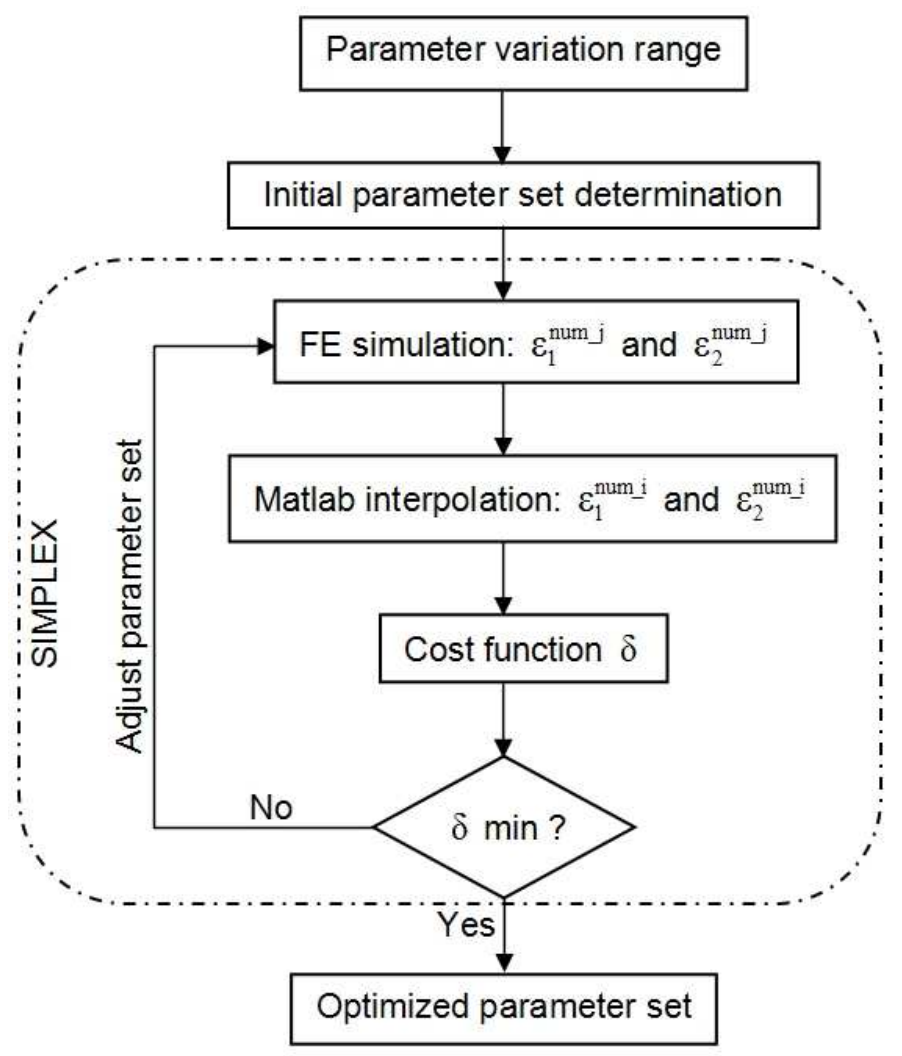

Fig. 17 Flowchart of the identification process with biaxial test 
Within the determined parameter variation range, 13 initial parameter sets were generated. They were used in the finite element simulation as the input data of a user subroutine. Then, the output principal strain values were interpolated with Matlab program, to compare with the experimental values via the cost function defined by Eq. (6). A new parameter set was then generated by Simplex algorithm as long as the cost function continued to decrease.

\subsection{Applications}

\subsection{1. $\quad$ AA5086}

Table 3 gives the optimized Bron and Besson parameter set for AA5086, the initial corresponding yield contour is presented Fig. 21(a). As mentioned above, several optimizations were carried out with different initial parameter sets. Only one optimized parameter set was found.

Table 3 Bron and Besson parameter set for AA5086

\begin{tabular}{ccccccc}
\hline $\mathrm{Y}_{0}(\mathrm{MPa})$ & $\mathrm{c}_{1}$ & $\mathrm{a}$ & $\mathrm{b}_{1}$ & $\mathrm{~b}_{2}$ & $\mathrm{c}_{1}^{1}$ & $\mathrm{c}_{2}^{1}$ \\
\hline 125.9 & 0.72 & 0.16 & 13.00 & 8.41 & 1.06 & 1.10 \\
\hline & $\mathrm{c}_{3}^{1}$ & $\mathrm{c}_{4}^{1}$ & $\mathrm{c}_{1}^{2}$ & $\mathrm{c}_{2}^{2}$ & $\mathrm{c}_{3}^{2}$ & $\mathrm{c}_{4}^{2}$ \\
\hline & 0.82 & 0.95 & 0.75 & 0.47 & 0.78 & 0.62 \\
\hline
\end{tabular}

The r-values calculated with Bron and Besson parameters given Table 3 are respectively $r_{0}=0.39, r_{45}=0.46$ and $r_{90}=0.37$. The calculated $0.2 \%$ proof stresses for the $0^{\circ}, 45^{\circ}$ and $90^{\circ}$ from the rolling direction are respectively $\sigma_{0}=146 \mathrm{MPa}, \sigma_{45}=145 \mathrm{MPa}$ and $\sigma_{90}=141 \mathrm{MPa}$. Those values must be compared to the experimental ones given in Table 1. As one can see, a good agreement is observed for the anisotropic coefficients whereas differences of $10 \%$ and $8.5 \%$ are approximately obtained respectively for $\sigma_{45}$ and $\sigma_{90}$.

Fig. 18(a), (b) and (c) compare the experimental principal strains and strain path ratio along diagonal direction with predictions by Hill 1948 and B\&B yield models respectively. For the 
major strain, Hill 1948 yield model leads to an overestimation of about $60 \%$ in the center and $25 \%$ at the diagonal corner. The predicted values with B\&B yield model are close to the experiments. However, there is still a difference between them, with an overestimation of about $10 \%$ in the center. For minor strain, B\&B predictions are better than Hill 1948 ones, which overestimate by about $60 \%$ the experimental data in the center. For the strain path ratio, the two models give a slight underestimation close to the specimen center. Above $4 \mathrm{~mm}$ from the center, only $\mathrm{B} \& \mathrm{~B}$ predictions vary accordingly to the experimental curve.

It can then be concluded that the parameter set for Bron and Besson yield criterion identified from the biaxial data lead to a very good description of the strain field along the diagonal direction. To go further and as a validation step, experimental data output in the longitudinal and transverse directions are then compared to the numerical predictions obtained with the two models.

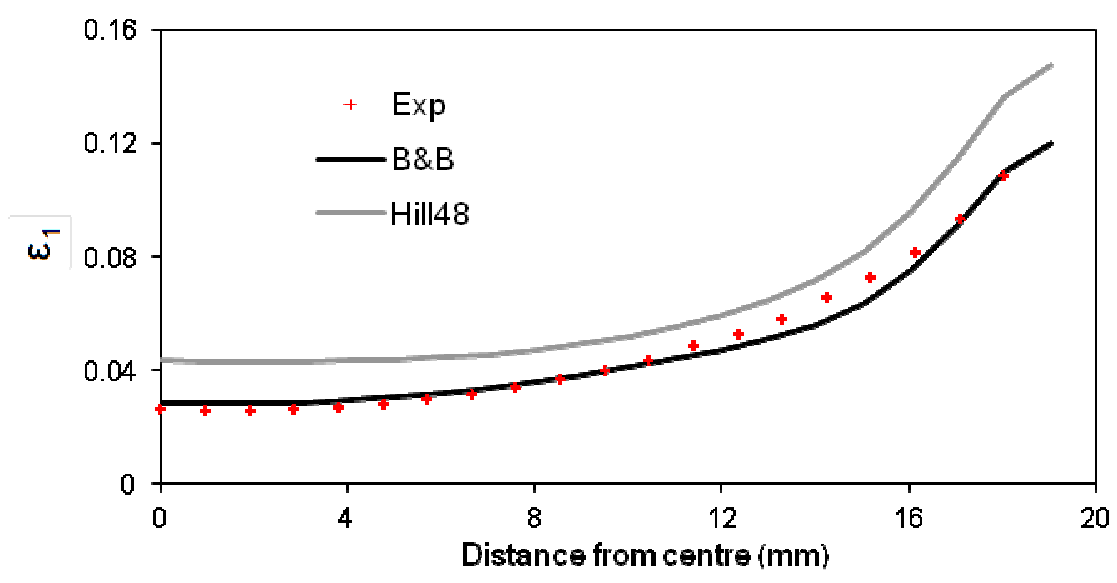

(a) : major strain

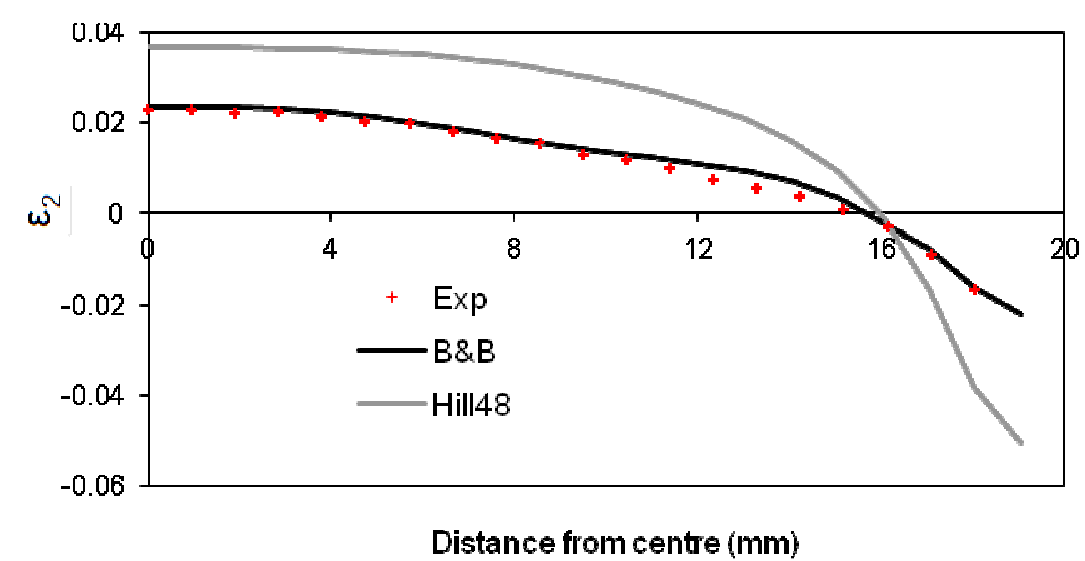

(b) : minor strain 


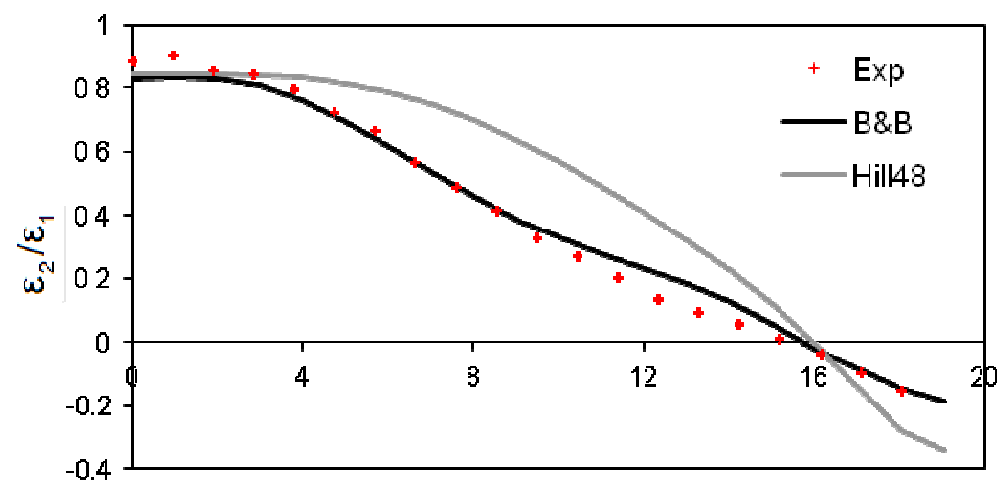

Distance from centre ( $(\mathrm{mm})$

(c) : strain path ratio

Fig. 18 Comparison between experimental and predicted principal strains and strain path ratio along the diagonal direction for AA5086

Fig. 19(a) compares the experimental major strain along longitudinal and transverse directions with predictions by Hill 1948 and B\&B yield models respectively. For Hill 1948 yield model, predicted values along the two directions are quite different. Both of them overestimate the first part of the paths and underestimate the rest of them. The overestimation in the center area is nearly up to $73 \%$. B\&B predictions give an overestimation by only $12 \%$ and $24 \%$ respectively for a distance below $4 \mathrm{~mm}$. And in this area, the predictions along rolling direction are slightly higher than the one along transverse direction, as observed in the experiments. Above a distance of $10 \mathrm{~mm}$ from the center, there is an underestimation of the major strain, as with Hill 1948 model. This underestimation seems to come from the fact that the experimental strain was measured just before the rupture. Necking in the cruciform specimen arm may have started in the experiments but may not be well predicted numerically.

Fig. 19(b) compares the minor strains. The prediction with Hill 1948 yield model leads to an overestimation along the whole path and for the two directions. The overestimation in the center is about $69 \%$. On the contrary, B\&B model gives a good description, though a slight overestimation of $7 \%$ can be noticed in the center, and it remains along the whole path. 
Fig. 19(c) compares the strain path ratios. Hill 1948 predictions do not stick to the experimental values at all, except for a distance below $4 \mathrm{~mm}$ from the center. However, the numerical result shows a bump along the transverse direction, as already shown and discussed in the experiments, but it occurs further along the direction than the experiments ( $6 \mathrm{~mm}$ instead of $4 \mathrm{~mm})$. For B\&B yield model, a perfect match for both directions is obtained up to $10 \mathrm{~mm}$. the bump along the transverse direction which is failed to be described by Hill 1948 yield model is precisely predicted by $\mathrm{B} \& \mathrm{~B}$ yield model.

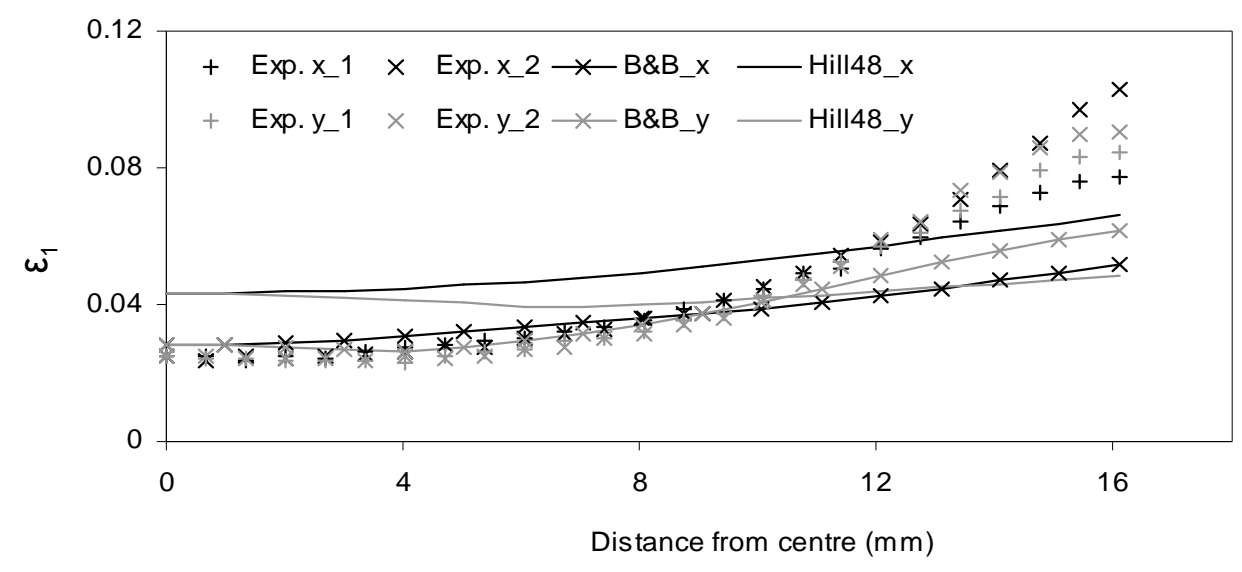

(a) : major strain

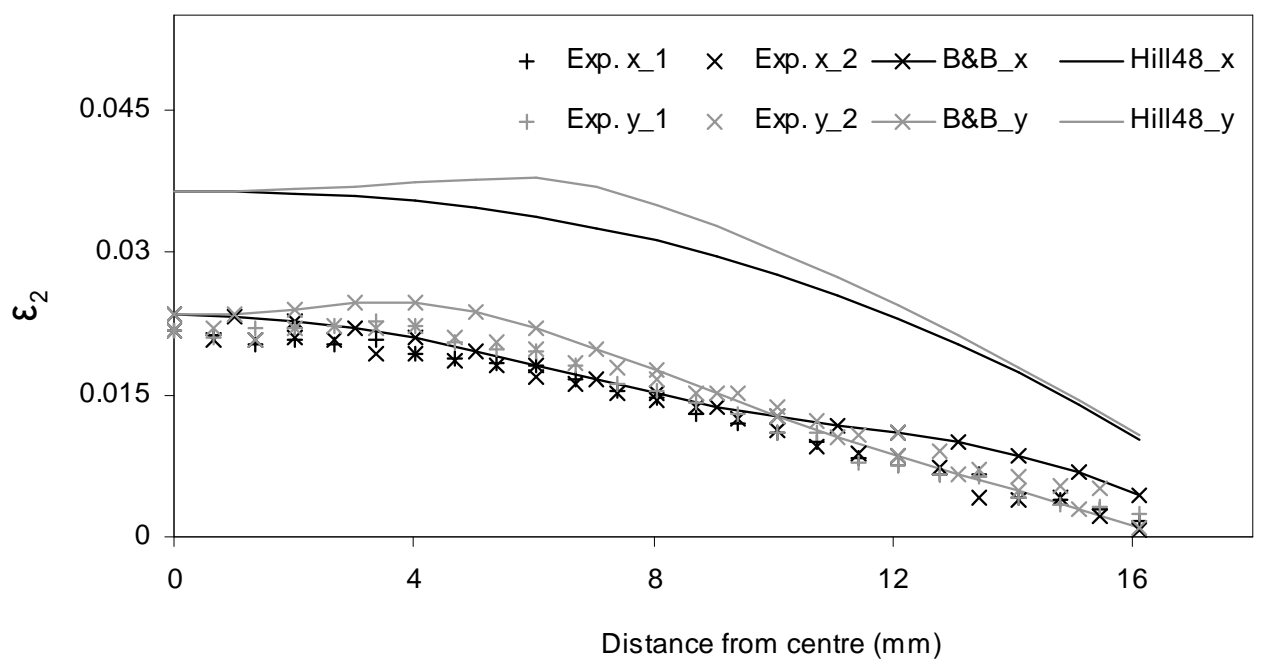

(b) : minor strain 


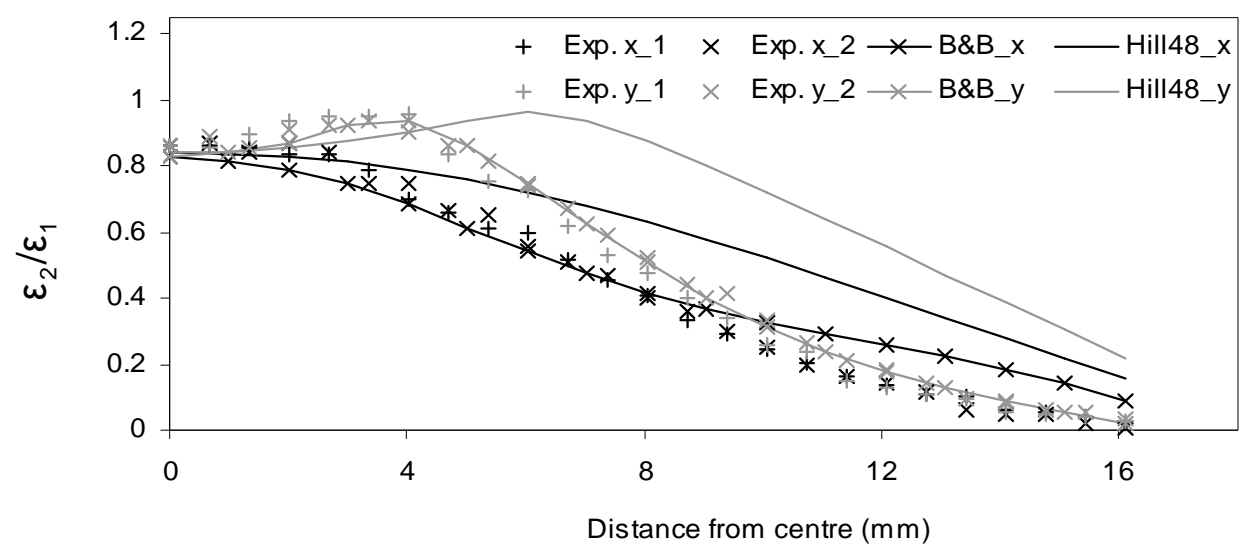

(c) : strain path ratio

\section{Fig. 19 Experimental and predicted strains and strain path ratios along the longitudinal and transverse directions for AA5086}

Through the above strain analysis in the central gauge area of the cruciform specimen, a sensitivity of the strain field to different yield criteria has been shown. It can also be seen that Hill 1948 strain field predictions are far away from the experimental values, while B\&B model describes it well. It can be concluded that the proposed parameter identification method with only a biaxial tensile test is really promising. The proposed method will now be applied to DP980 in the following part.

\subsubsection{DP980}

The identification for DP980 was carried out with the average values along diagonal direction at $\mathrm{t}=2.0 \mathrm{~s}$. This instant is far away from the rupture, in order to avoid the influence of necking. Table 4 gives the optimized Bron and Besson parameter set for DP980, the initial corresponding yield contour is presented Fig. 21(b).

The r-values calculated with Bron and Besson parameters, presented Table 4, are respectively $r_{0}=0.61, r_{45}=0.35$ and $r_{90}=1.03$. The calculated $0.2 \%$ proof stresses for the $0^{\circ}, 45^{\circ}$ and $90^{\circ}$ from the rolling direction are respectively $\sigma_{0}=701 \mathrm{MPa}, \sigma_{45}=829 \mathrm{MPa}$ and $\sigma_{90}=784 \mathrm{MPa}$. 
Table 4 Bron and Besson parameter set for DP980

\begin{tabular}{ccccccc}
\hline $\mathrm{Y}_{0}(\mathrm{MPa})$ & $\mathrm{c}_{1}$ & $\mathrm{a}$ & $\mathrm{b}_{1}$ & $\mathrm{~b}_{2}$ & $\mathrm{c}_{1}^{1}$ & $\mathrm{c}_{2}^{1}$ \\
\hline 135.9 & 0.34 & 9.78 & 6.77 & 2.84 & 0.77 & 0.92 \\
\hline & $\mathrm{c}_{3}^{1}$ & $\mathrm{c}_{4}^{1}$ & $\mathrm{c}_{1}^{2}$ & $\mathrm{c}_{2}^{2}$ & $\mathrm{c}_{3}^{2}$ & $\mathrm{c}_{4}^{2}$ \\
\hline & 0.90 & 0.42 & 0.87 & 1.08 & 0.79 & 0.76 \\
\hline
\end{tabular}

Fig. 20(a) shows the predicted and experimental major and minor strain evolution along the diagonal path. It can be shown that there is a very good agreement between experiments and numerical simulation. However, an overestimation of about $10 \%$ is noticed for the major strain in the specimen center. The strain path ratio along the diagonal direction was also compared with the experimental value in Fig. 20(b). Bron and Besson model gives a slight underestimation at the beginning of the curve, in the central area of the cruciform specimen. However, farther from the center, the prediction is rather close to the experiments.

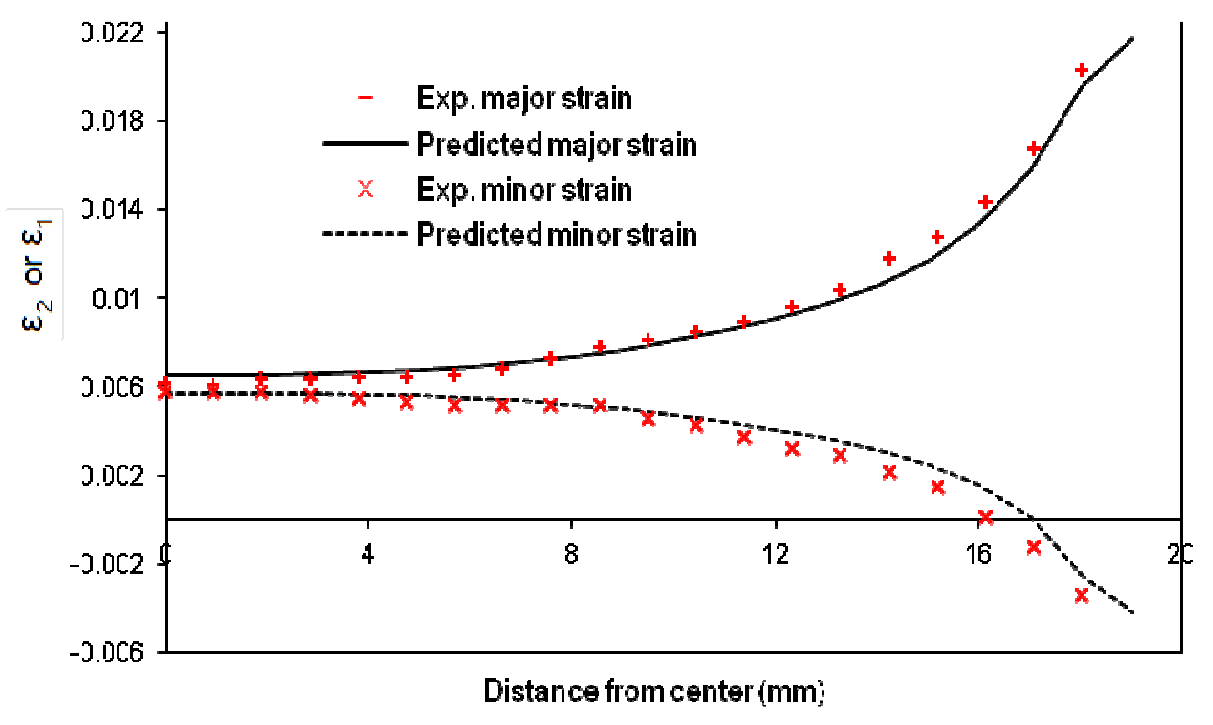

(a): Experimental and predicted principal strains 


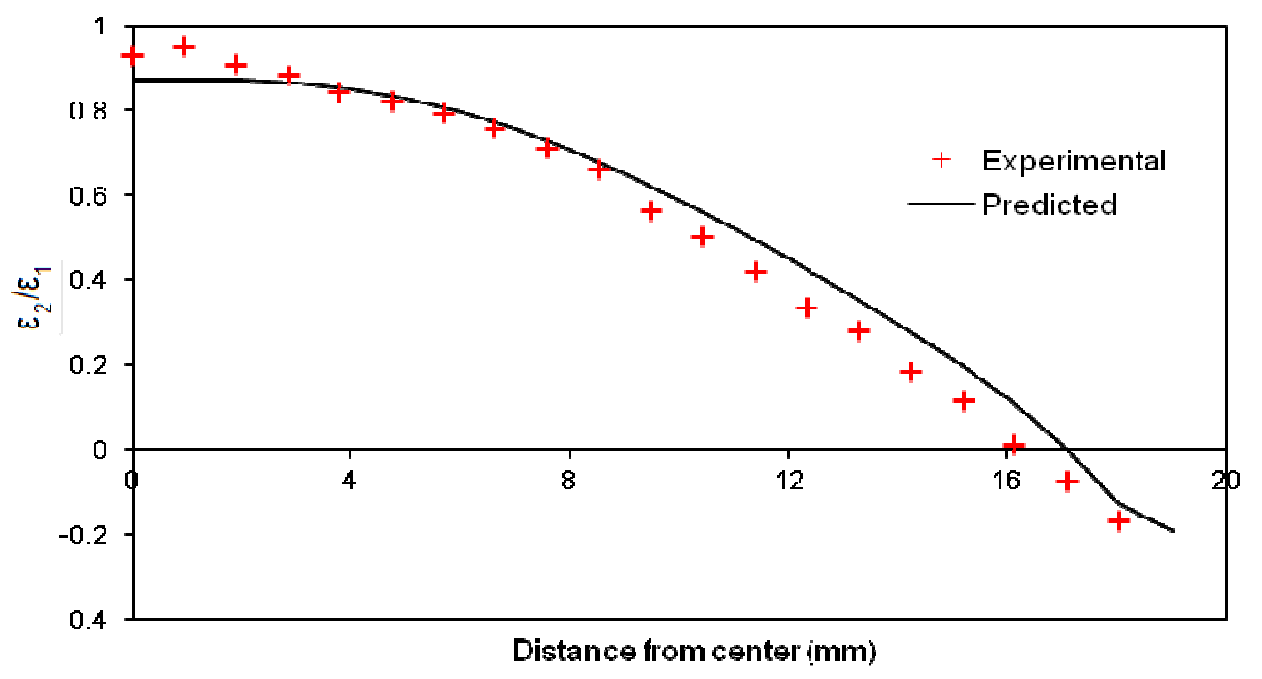

(b) : Experimental and predicted strain path ratios

Fig. 20 Predictions along diagonal direction by Bron and Besson parameter set for DP980: (a) principal strains; (b) strain path ratio

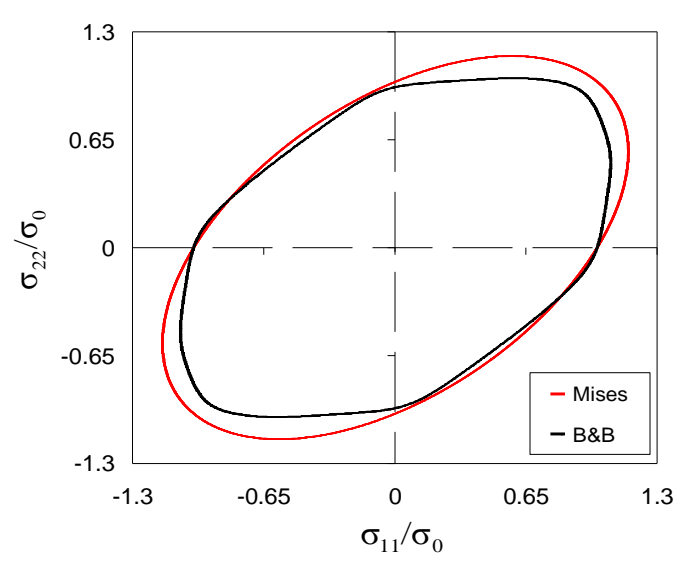

(a)

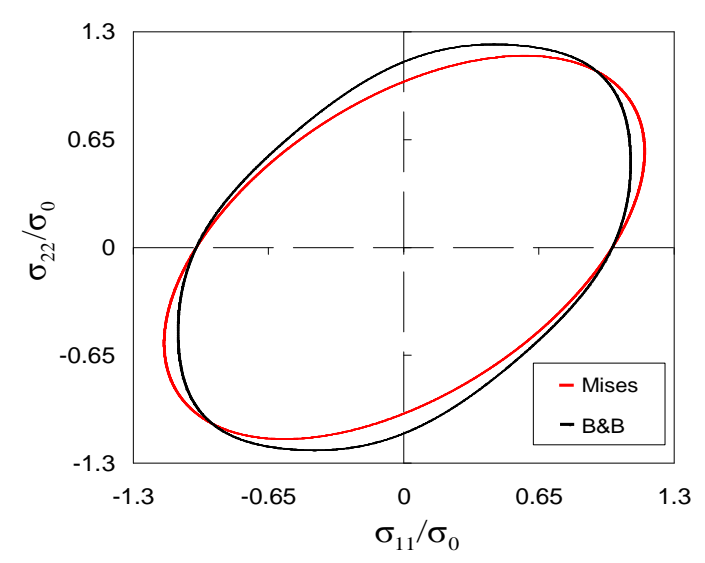

(b)

Fig. 21 Bron \& Besson and Mises initial yield contours

(a) AA5086 - (b) DP980

\section{Conclusion}

In this work, biaxial tensile tests were carried out for an aluminum alloy AA5086 and a dual phase steel DP980, using a specifically designed cruciform specimen. The strain field in the central gauge area of each specimen was analyzed during the test, using digital image correlation, and major and minor strains, as well as the ratio of the minor strain over the major strain (or strain path ratio), were in particular investigated along specific paths, i.e. longitudinal, transverse and 
diagonal. The overall strain level reached before rupture depends on the material, and is larger for AA5086 than for DP980. Moreover, a rather large variation of the strain path ratio was evidenced, as well as quasi-linear strain paths up to rupture. And the strain field seems sensitive to the anisotropy of the material. Consequently, a parameter identification process for Bron and Besson anisotropic yield model was proposed, involving finite element simulation of the test and minimization of the gap between experimental and numerical principal strains along the diagonal direction. A very good description of the strain field was thus obtained. Moreover, longitudinal and transverse directions were used out of validation purposes, in the case of the aluminium alloy, showing again that, for strain level far enough from the onset of necking, a close description of the experimental major and minor strains was obtained. The biaxial tensile test can be therefore considered as an interesting tool for material parameter identification.

\section{References}

[1] Hill R (1948) A theory of the yielding and plastic flow of anisotropic metals. Proc R Soc of Lond. Ser Math Phys Sci 193: 281-297.

[2] Barlat F, Lege DJ, Brem JC (1991) A six-component yield function for anisotropic materials. Int J Plast 7: 693-712.

[3] Barlat F, Brem JC, Yoon JW, Chung K, Dick RE, Lege DJ, Pourboghrat F, Choi SH, Chu E (2003) Plane stress yield function for aluminum alloy sheets—part 1: theory. Int J Plast 19: $1297-1319$.

[4] Barlat F, Aretz H, Yoon JW, Karabin ME, Brem JC, Dick RE (2005) Linear transfomation-based anisotropic yield functions. Int J Plast 21: 1009-1039.

[5] Bron F, Besson J (2004) A yield function for anisotropic materials Application to aluminum alloys. Int J Plast 20: 937-963. 
[6] Banabic D (2010) Sheet metal forming processes: Constitutive modeling and numerical simulation. Springer.

[7] Aretz H (2005) A non-quadratic plane stress yield function for orthotropic sheet metals. J Mater Process Technol 168: 1-9.

[8] Aretz H, Hopperstad O,. Lademo O (2007) Yield function calibration for orthotropic sheet metals based on uniaxial and plane strain tensile tests. J Mater Process Technol 186: 221-235.

[9] Aretz H (2004) Applications of a new plane stress yield function to orthotropic steel and aluminium sheet metals. Model Simul Mater Sci Eng 12: 491-509.

[10] Banabic D, Kuwabara T, Balan T, Comsa DS (2004) An anisotropic yield criterion for sheet metals. J Mater Process Technol 157-158: 462-465.

[11] Comsa DS, Banabic D (2008) Plane-stress yield criterion for highly-anisotropic sheet metals. NUMISHEET 2008, Interlaken, Switzerland, pp 43-48.

[12] $\mathrm{Hu} \mathrm{W}$ (2007) Constitutive modeling of orthotropic sheet metals by presenting hardening-induced anisotropy. Int J Plast 23: 620-639.

[13] Zang SL, Thuillier S, Le Port A, Manach PY (2011) Prediction of anisotropy and hardening for metallic sheets in tension, simple shear and biaxial tension. Int J Mech Sci 53: $338-347$.

[14] Wang H, Wan M, Wu X, Yan Y (2009) The equivalent plastic strain-dependent Yld2000-2d yield function and the experimental verification. Comput Mater Sci 47: 12-22.

[15] Zang S, Lee M (2011) A General Yield Function within the Framework of Linear Transformations of Stress Tensors for the Description of Plastic - strain - induced Anisotropy. AIP Conf Proc 1383: 63-70. 
[16] Grédiac M (2004) The use of full-field measurement methods in composite material characterization: interest and limitations. Compos Part A 35: 751-761.

[17] Avril S, Bonnet M, Bretelle A, Grediac M, Hild F, Ienny P, Latourte F, Lemosse D, Pagano S, Pagnacco E, Pierron F (2008) Overview of identification methods of mechanical parameters based on full-field measurements. Exp Mech 48: 38-402.

[18] Güner A, Soyarslan C, Brosius A, Tekkaya A.E (2012) Characterization of anisotropy of sheet metals employing inhomogeneous strain fields for Yld2000-2D yield function. International Journal of Solids and Structures, 49-25, 3517-3527.

[19] Latourte F (2007) Identification des paramètres d'une loi elastoplastic de prager et calcul de champs de contrainte dans des matériaux heterogènes. PhD thesis at Université Montpellier II Sciences et Techniques du Languedoc.

[20] Pottier T, Vacher P, Toussaint F, Louche H, Coudert T (2012) Out-of-plane testing procedure for inverse identification purpose: application in sheet metal plasticity. Exp Mech 52: 951-963.

[21] Lubineau G (2009) A goal-oriented field measurement filtering technique for the identification of material model parameters. Comput Mech 44: 591-603.

[22] Blaysat B, Florentin E, Lubineau G and Moussawi A (2012) A dissipation gap method for full-field measurement-based identification of elasto-plastic material parameters. Int $J$ Num Method Engineer 91: 685-704.

[23] Kulawinski D, Nagel K, Henkel S, Hübner P, Fischer H, Kuna M, Biermann H (2011) Characterization of stress-strain behavior of a cast TRIP steel under different biaxial planar load ratios. Eng Fract Mech 78: 1684-1695.

[24] Prates PA, Fernandes JV, Oliveira MC, Sakharova NA, Menezes LF (2010) On the 
characterization of the plastic anisotropy in orthotropic sheet metals with a cruciform biaxial test. IOP Conf Ser: Mater Sci Eng 10: 1-10.

[25] Teaca M, Charpentier I, Martiny M, Ferron G (2010) Identification of sheet metal plastic anisotropy using heterogeneous biaxial tensile tests. Int J Mech Sci 52: 572-580.

[26] Ferron G, Makkouk R, Morreale J (1994) A parametric description of orthotropic plasticity in metal sheets. Int J Plast 10: 431-449.

[27] Hayhurst DR (1973) A biaxial-tension creep-rupture testing machine. J Strain Anal Eng Des 8: $119-123$.

[28] Ferron G, Makinde A (1988) Design and development of a biaxial strength testing device. J Test Eval 16: 253-256.

[29] Fraunhofer (2005) Dynamic material testing.

[30] Makinde A, Thibodeau L, Neale KW (1992) Development of an apparatus for biaxial testing using cruciform specimens. Exp Mech 32: 138-144.

[31] Leotoing L, Guines D, Zhang S, Ragneau E (2013) A cruciform shape to study the influence of strain paths on forming limit curves. Key Eng Mater 554-557: 41- 46.

[32] Makinde A, Thibodeau L, Neale KW, Lefebvre D (1992) Design of a biaxial extensometer for measuring strains in cruciform specimens. Exp Mech 32: 132-137.

[33] Zhang S, Léotoing L, Guines D, Thuillier S, Zang S (2014) Calibration of anisotropic yield criterion with conventional tests or biaxial test. Int J Mech Sci 85: 142-151.

[34] Ohtake Y, Rokugawa S, Masumoto H (1999) Geometry determination of cruciform- type specimen and biaxial tensile test of C/C composites. Key Eng Mater 164-165: 151-154. 
[35] Zhang S (2014) Characterization of anisotropic yield criterion with biaxial tensile test. $\mathrm{PhD}$ thesis at INSA de Rennes.

[36] Müller W, Pöhlandt K (1996) New experiments for determining yield loci of sheet metal. J Mater Process Technol 60: 643-648.

[37] Banabic D, Siegert K (2004) Anisotropy and formability of AA5182-0 aluminium alloy sheets. CIRP Ann - Manuf Technol 53: 219-222.

[38] Kuwabara T, Ikeda S, Kuroda K (1998) Measurement and analysis of differential work hardening in cold-rolled steel sheet under biaxial tension. J Mater Process Technol 80-81: $517-523$.

[39] Hill R, Hutchinson JW (1992) Differential hardening in sheet metal under biaxial loading: a theoretical framework. J Appl Mech 59: S1-S9.

[40] Zidane I, Guines D, Leotoing L, Ragneau E (2010) Development of an in-plane biaxial test for forming limit curve (FLC) characterization of metallic sheets. Meas Sci Technol 21: 055701.

[41] Lecompte D, Smits A, Sol H, Vantomme J and Van Hemelrijck D (2007) Mixed numerical-experimental technique for orthotropic parameter identification using biaxial tensile test on cruciform specimens. Int J Sol Struct 44: 1643-1656.

[42] Périé J N, Leclerc H, Roux S, Hild F (2009) Digital image correlation and biaxial test on composite material for anisotropic damage law identification. Int J Sol Struct 46: 2388-2396.

[43] Promma N, Raka B, Grédiac M, Toussaint E, LeCam J B, Balandraud X and Hild F. 
Application of the virtual fields method to mechanical characteriza-tion of elastomeric materials (2009) Int J Sol Struct 46: 698-715.

[44] Mishra A, Thuillier S (2014) Investigation of the rupture in tension and bending of DP980 steel sheet. Int J Mech Sci 84C: 171-181.

[45] Piecewise cubic hermite interpolating polynomial (PCHIP) for given data in MATLAB and then finding area. http://stackoverflow.com/questions/17140658/piecewise-cubic-hermiteinterpolating-polynomial-pchip-for-given-data-in-matla. Accessed: 17 April 2014.

[46] ModeFrontier | ESTECO. http://www.esteco.com/modefrontier. Accessed: 03 November 2013.

[47] Simplex Optimization. http://www.chem.uoa.gr/applets/AppletSimplex/Appl_Simplex2. html. Accessed: 10 April 2014.

[48] Meuwissen M.H.H, Oomens C.W.J, Baaijens F.P.T, Petterson R and Janssen J.D, (1998) Determination of the elasto-plastic properties of aluminium using a mixed numerical-experimental method. Journal of Material Processing Technology, 75, 204-211.

[49] Cooreman S, Lecompte D, Sol H, Vantonne J, Debruyne D, (2007) Elasto-plastic material parameter identification by inverse methods: Calculation of the sensitivity matrix. International Journal of Solids and Structures, 44, 4329-4341.

[50] Pottier T, Toussaint F, Vacher P, (2011) Contribution of heterogeneous strainfield measurements and boundary conditions modelling in inverse identification of material parameters. European Journal of Mechanics A/Solids. Vol. 30, pages 373-382. 
